\title{
Fracture Characteristics Analysis of Pressured Pipeline with Crack Using Boundary Element Method
}

\author{
Han-Sung Huang \\ Graduate Institute of Engineering Science and Technology, National Kaohsiung First University of Science and Technology, \\ Kaohsiung City 824, Taiwan \\ Correspondence should be addressed to Han-Sung Huang; hansungh@gmail.com
}

Received 18 September 2014; Revised 10 March 2015; Accepted 16 March 2015

Academic Editor: Peter Majewski

Copyright (C) 2015 Han-Sung Huang. This is an open access article distributed under the Creative Commons Attribution License, which permits unrestricted use, distribution, and reproduction in any medium, provided the original work is properly cited.

Metal materials can inevitably show deteriorated properties by the factors of stress, temperature, and environmental erosion in distinct operating environments. Without proper protection, the service life would be shortened or even deadly danger would be caused. This study aims to apply Finite Element Method and Boundary Element Method to analyzing the effects of corroded petrochemical pipes on the fatigue life and the fracture form. The research results of nondestructive testing and software analyses show that cracked oil pipes with uniform corrosion bear larger stress, mainly internal pressure, on the longitudinal direction than the circumferential direction. As a result, the maximal fatigue loading cycle of a circumferential crack is higher than that of a longitudinal one. From the growing length and depth of a crack, the final aspect ratio of crack growth appears in 2.42-3.37 and 2.71-3.42 on the circumferential and longitudinal direction, respectively. Meanwhile, the ratios of loading cycles of circumferential and longitudinal crack are 26.23 on uncorroded and 20.54 on general metal loss oil pipe. The complete crack growth and the correspondent fatigue loading cycle could be acquired to determine the service life of the oil pipe being operated as well as the successive recovery time.

\section{Introduction}

Steel and other metal materials have been widely applied to commodity industry, building equipment, means of transportation, and nuclear power. Nevertheless, metal materials are likely to affect the deterioration of properties by stress, temperature, and environmental erosion in different operating environments. They would gradually reduce the designed effectiveness, shorten the service life, and even result in deadly danger without being properly protected. Corrosion and fracture reveal higher proportion in the application process of materials. According to the statistics of American National Standards Institute, the economic loss of one hundred billion US dollars, about $4.2 \%$ of gross national product, in the USA is caused by material fracture; one-third of the loss could be protected and avoided by known technologies, and one-fourth of it could be reduced by research and development.

Consequently, it is an important research direction to reduce the resource waste resulting from corrosion.
Corrosion could be defined as material fracture caused by chemical, electrochemical, or metallurgical functions in the environment, which usually occurs slowly but still remains the property. Corrosion is regarded as an electrochemical reaction, causing some parts or the entire part of metal to be ionized. It requires electric current passing the electrolytic solution, which could be ordinary water, salted water, or acidbase solution with any concentration, on some regions of the metal surface. The factors in material corrosion are classified as follows:

(1) chemical corrosion,

(2) electrochemical corrosion.

Chemical corrosion, also called direct dissolution, refers to materials being placed in the environment with dissoluble solution till the materials are completely corroded or the solution achieves the saturation point. Other conditions, like high temperature and humidity, could accelerate the oxygenation of materials to result in corrosion. Electrochemical corrosion 
generally refers to two types of heterogeneous metal or metal being able to construct both poles with potential difference and forming anode metal, which is constantly deionized into metal ions and corroded in the environment connecting with electrolytes. Electrochemical corrosion presents better importance on such two types of corrosion but is more easily ignored.

Disastrous fracture failure of general engineering structures is caused by cracks beyond safety. All structural cracks, no matter they are production defects or resulted from operational local damage, could, to some extent, cause crack growth through fatigue, stress corrosion, or creep. Crack propagation could result in decreasing structural intensity so that fracture would appear when the residual strength cannot continuously bear load. Such a mechanism occurs when a cyclic loading fatigue crack, which slowly develops in normal conditions, grows and rapidly results in disastrous events. Determination of damage tolerance is a process which could continuously estimate the service life of a structure with cracks. As a result, any fracture control plans are based on the determination of damage tolerance that the fracture control information is composed of the following points.

(1) The maximal allowance size is evaluated with the residual intensity of a crack structure.

(2) The service time for the maximal allowance crack size is deducted with the time function of crack propagation and the secure operation life for defining structures.

(3) Linear elastic fracture mechanics damage tolerance analysis is applied to describing crack behaviors. Linear elastic fracture mechanics assumes that crack behaviors are determined merely by the loading and Stress Intensity Factor of the function of the geometric shape of a structure. Stress Intensity Factor plays a critical role in the application of linear elastic fracture mechanics.

(4) The crack growth is achieved by simulating the crack propagation increment analysis. The crack propagation of each increment is proceeded by stress analysis and Stress Intensity Factor evaluation. The crack propagation path is, based on the predicted increment, calculated by the Stress Intensity Factor defined in the growth standard to acquire the propagation direction.

Generally, a crack with complicated geometric shapes and continuous growth and changing path in an engineering structure is evaluated by the Stress Intensity Factor with numerical calculation. Finite Element Method has been applied to fracture mechanics for a long period of time, which could be referred to in the relevant research of Gallagher [1] and Rice and Tracey [2] and is recently widely applied to the research on crack growth. The method can also be used to solve many engineering problems, for example, the plasticity $[3,4]$ and acoustic propagation [5].

Boundary Element Method has been a complete numerical technique in fracture mechanics analysis. Brebbia and Dominguez [6] successfully utilized Boundary Element

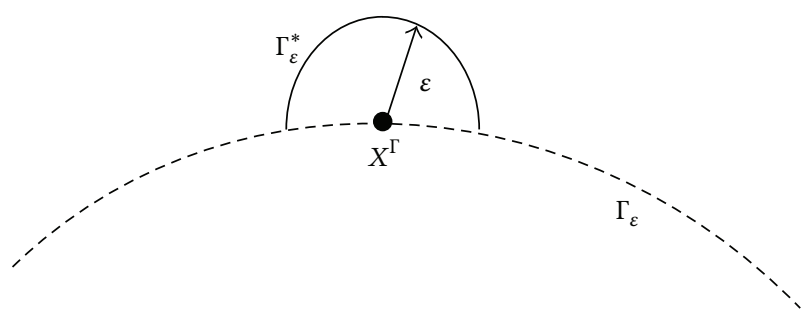

FIGURE 1: Source point on the boundary rounded by a semicircle.

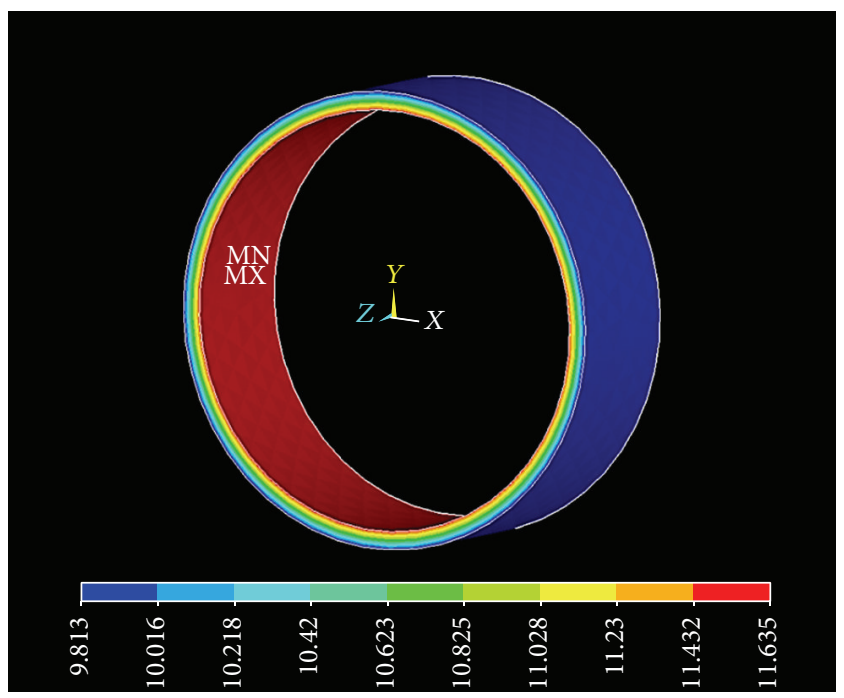

FIGURE 2: Stress distribution of an uncorroded oil pipe with internal pressure.

Method in the displacement boundary integral equation for the problems of geometric linear elasticity mechanics with deterioration. Such deterioration could be defined as mathematical cracks, where the displacement field is discontinuous, including the internal or marginal surface without area and volume boundary. In terms of symmetric cracks, merely one surface requires modeling cracks, and Boundary Element Method with a single region could also be used for the analysis. Nonetheless, solving general crack problems with Boundary Element Method could not be directly applied to a single field analysis. For this reason, some special techniques have been applied to overcome such a difficulty, including crack Green's function proposed by Snyder and Cruse [7], displacement discontinuity proposed by Crouch [8], and subregions proposed by Blandford et al. [9]. A full history of the Dual Boundary Element Methods with emphasis on hypersingular integrals and divergent series can be found in this review article [10].

Bueckner [11] first utilized dual integral equation for solving crack problems. Watson [12], on the other hand, first developed dual integral equation from Boundary Element Method by forming the expression with displacement equation and the normal differentiation. The theory of such an expression was based on Hong and Chen [13] combining displacement and external force integral equation. When displacement and traction boundary integral equation could 


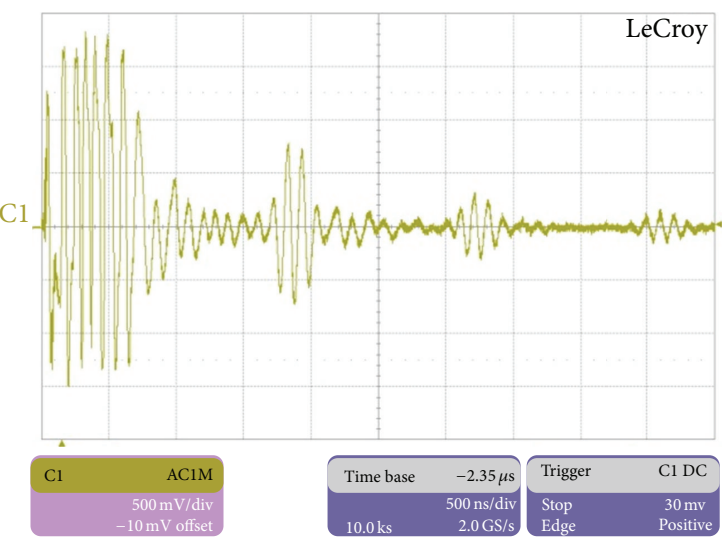

(a)

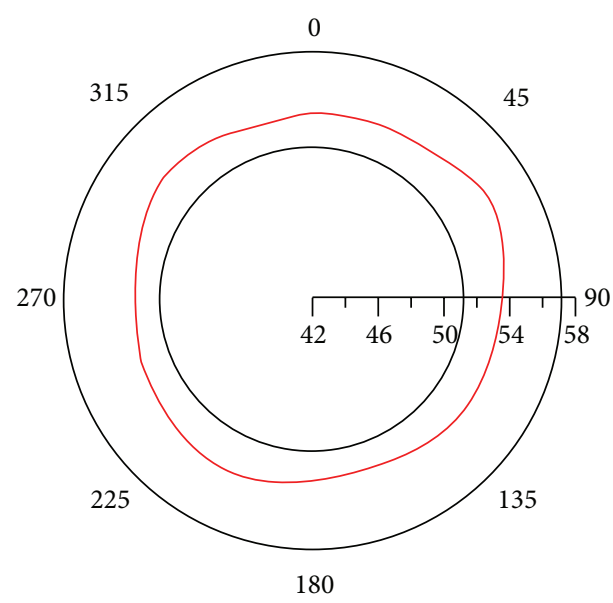

(b)

FIGURE 3: Ultrasonic testing echo and the longitudinal thickness distribution of the tested oil pipe with metal loss.

be simultaneously implemented on the crack boundary, general crack problems in a single region could be solved with Dual Boundary Element Method. Although there were still some problems of crack boundary coincide after integrating the path, individual boundary integral equation was distinct. Dual integral equation could be applied to solving various $3 \mathrm{D}$ problems, including $3 \mathrm{D}$ potential problem ([14], Gray) and 3D elasticity mechanics problem ([15], Gray et al.). Such two equations were analyzed by hypersingular integral surrounding the plane element. Such an approach required the nonstandard boundary interpolating function set surrounding a node and restricted the analysis being merely used for plane elements. Moreover, such an approach could not be applied to the propagation problem of marginal cracks. Dual integral equation was also applied to solving 2D elasticity mechanics problems and proposed to be merely used for embedded cracks [12].

Recently, Wen et al. [16] used the Dual Boundary Element Method to calculate dynamic Stress Intensity Factors for three-dimensional cracked structures in Laplace domain. dell'Erba and Aliabadi [17] developed a decomposition technique for mixed-mode Stress Intensity Factors to solve the three-dimensional thermoelasticity problem using a Boundary Element Method. Lu and $\mathrm{Wu}$ [18] introduced the stepby-step time integration technique into dual reciprocity Boundary Element Method to analyze the two-dimensional dynamic crack problems. Consequently, the singularity of algebraic equations was overcome by the sub-region Boundary Element Method. Keppas and Anifantis [19] developed a subdomain boundary element procedure to predict the fatigue life of elastic media with cyclic transient thermal loads. Several cases of pure opening or mixed fracture mode were studied. Guz et al. [20] reviewed the research in the dynamic fracture mechanics of materials with interface cracks in three-dimensional problems. Based on boundary integral equation and Boundary Element Method, a method for solving three-dimensional linear dynamic problems for piecewise-homogeneous materials is presented.
Aiming at fracture mechanics characteristics caused by the crack on an oil pipe bearing repeated pressure and crack growth, two cases are discussed in this study:

(1) an initially installed oil pipe not being corroded and fractured but merely presenting cracks resulting from the production,

(2) an oil pipe corroded by general metal loss with the crack locating on the maximal thinning area.

The crack direction is divided into circumferential direction and longitudinal direction. With the two cases, four analysis results are presented. ANSYS is first applied to analyze the stress caused by an oil pipe with internal pressure for the maximal stress area. The file format is then converted into the format of BEASY for calculating Stress Intensity Factor of the crack. Following the crack growth rules to step by step calculate the crack size in different loading cycles till the crack goes through the oil pipe wall.

\section{Research Principle}

2.1. Fracture Mechanics. In the fracture process of research materials or components, remote loading and residual stress are normally used for predicting the stress state close to the crack tip. The quantitative indicator is Stress Intensity Factor (SIF), and the material is assumed to be homogeneous, linear elastic properties and can be applied to brittle materials with fracture standards. It is also an important technique in damage tolerance analysis. The value of $K$ is generally related to the geometric shape of samples and the crack size and location; and the load on the material and the distribution model are correlated.

Three linear independent crack models, Modes I, II, and III, are utilized in fracture mechanics. Among the three modes, Mode I is an opening or tensile mode where the crack surface would be directly separated; Mode II is a sliding or in-plane shear mode where the two surfaces of the crack would move toward each other along the tip; and Mode III 


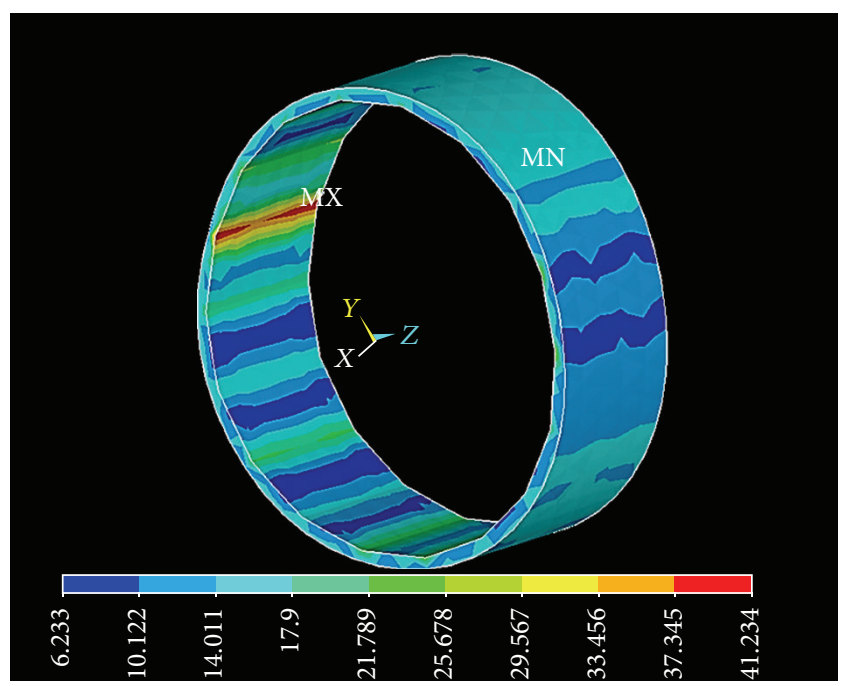

FIGURE 4: Stress distribution of an oil pipe bearing general metal loss.

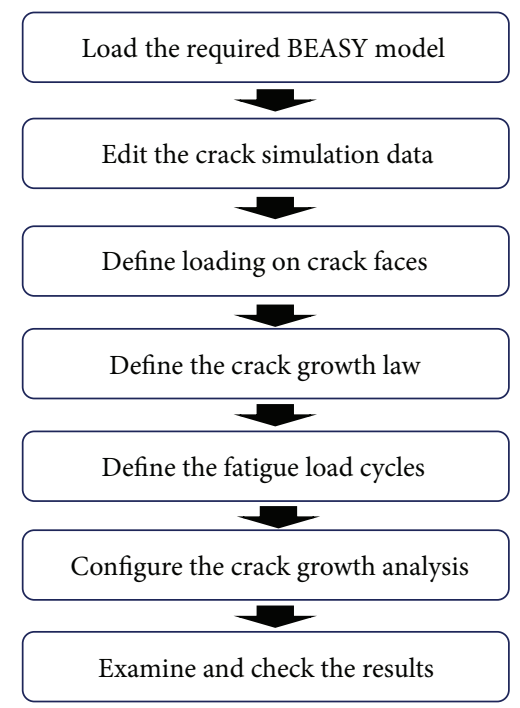

FIGURE 5: Simulation processes for the crack growth analysis.

is a tearing or antiplane shear mode where the crack surface would move vertically towards both sides along the crack front. Generally, Stress Intensity Factor of Mode I is shown as $K_{\mathrm{I}}$, and those of Modes II and III are shown as $K_{\mathrm{II}}$ and $K_{\mathrm{III}}$. The mathematical equations are presented as follows:

$$
\begin{aligned}
& K_{\mathrm{I}}=\lim _{r \rightarrow 0} \sqrt{2 \pi r} \sigma_{y y}(r, 0), \\
& K_{\mathrm{II}}=\lim _{r \rightarrow 0} \sqrt{2 \pi r} \sigma_{y x}(r, 0), \\
& K_{\mathrm{III}}=\lim _{r \rightarrow 0} \sqrt{2 \pi r} \sigma_{y z}(r, 0),
\end{aligned}
$$

where $\sigma_{i j}$ is predicted stress distribution close to the crack tip.

Stress Intensity Factor $K$ is a parameter determined by stress and geometric parameter $Y$ is also included. The stress intensity under any models presents direct proportion to the

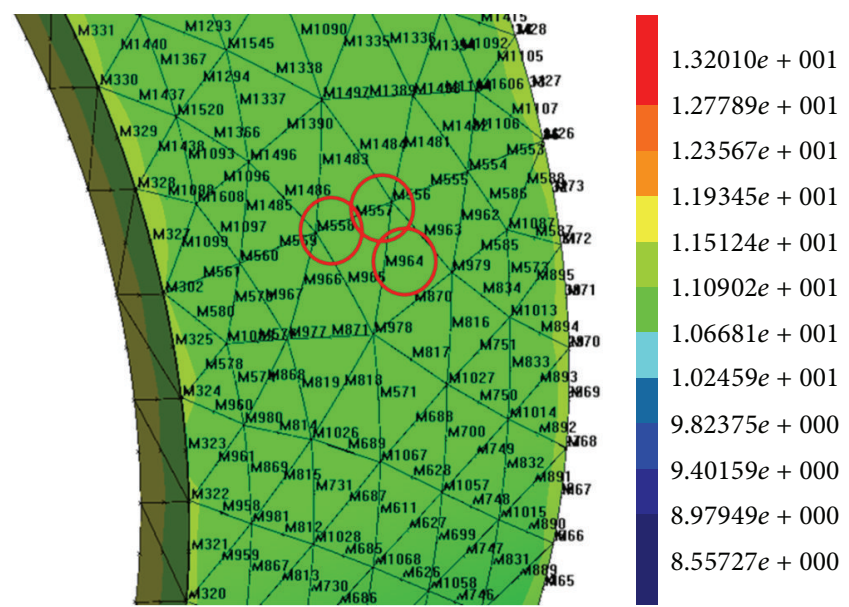

Principal stress (max-alg)

$$
\begin{aligned}
& \operatorname{Max}=13.248 \\
& \operatorname{Min}=8.5099
\end{aligned}
$$

FIGURE 6: Crack setting location of an uncorroded oil pipe but with cracks resulting from the production.

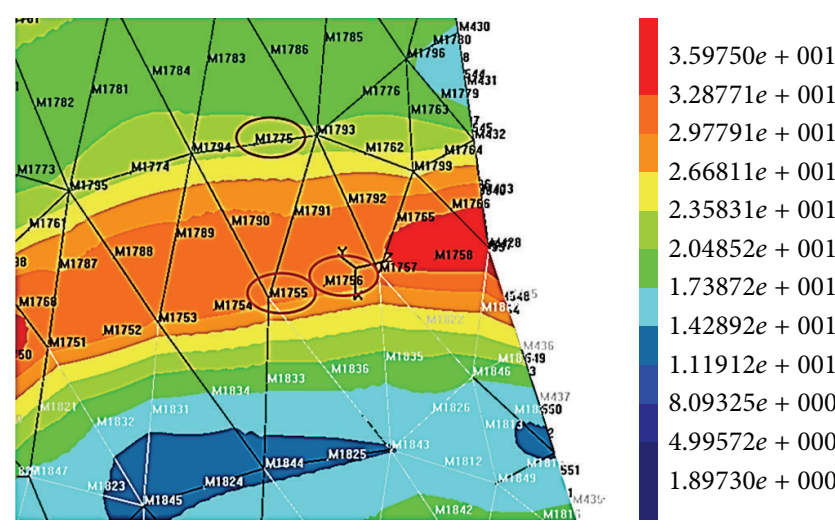

Principal stress (max-alg)

$\operatorname{Max}=36.323$

$\operatorname{Min}=1.5496$

FIGURE 7: Crack setting location of an oil pipe with general metal loss corrosion and the crack appearing on the maximal thinning.

load on the material. When a sharp crack is produced on the material, the minimum $K_{\mathrm{I}}$ could be determined through experiments, which is also the critical stress intensity along the crack. Under plane strain Mode I load, the critical value is critical fracture toughness (KIC) of the material. The unit for $\mathrm{KIC}$ is the square root of the product of stress and distance, showing the fracture stress of the material would gradually achieve KIC through the crack propagation. Critical Stress Intensity Factor KIC in Mode I is generally used for the design parameter in fracture mechanics. For the designs of bridges, buildings, and airplanes, the relevant design damage tolerance needs to be understood. Polishing could not help detect cracks. Generally speaking, a visible crack would be close to the critical stress state predicted by Stress Intensity Factor. 

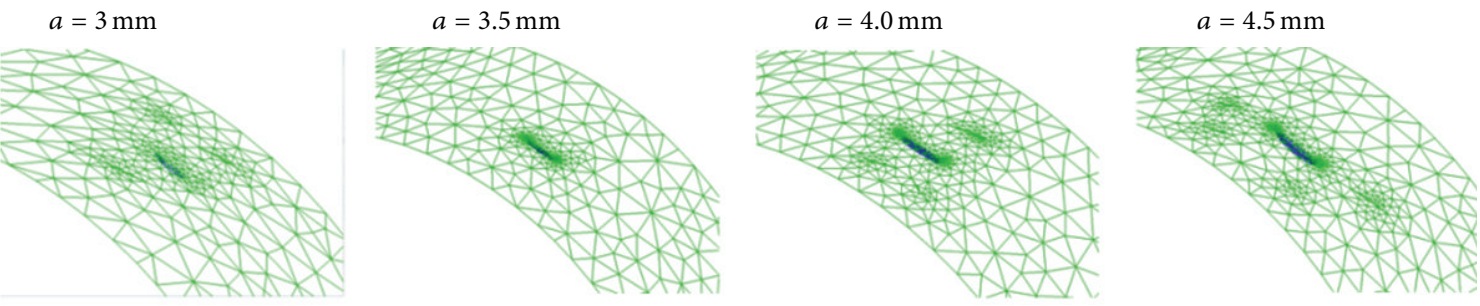

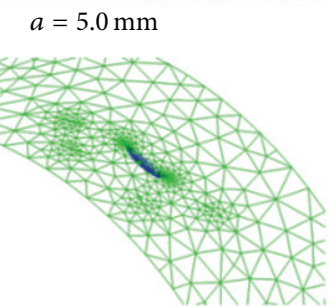

$a=5.5 \mathrm{~mm}$

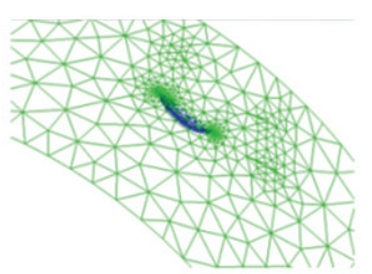

$a=7.5 \mathrm{~mm}$
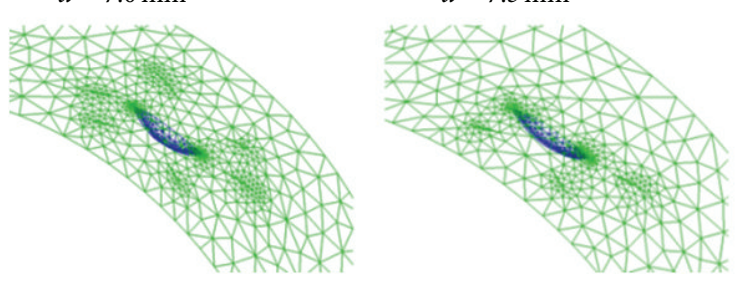

$a=6.0 \mathrm{~mm}$

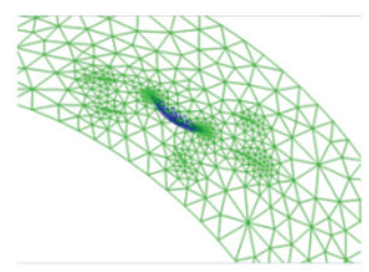

$a=8.0 \mathrm{~mm}$

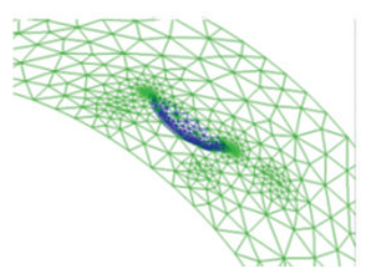

$a=6.5 \mathrm{~mm}$

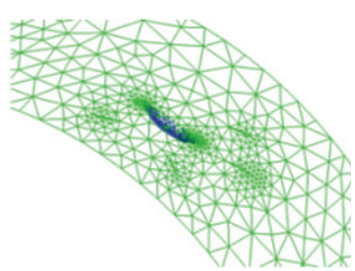

FIGURE 8: Growing shape and size of circumferential crack.

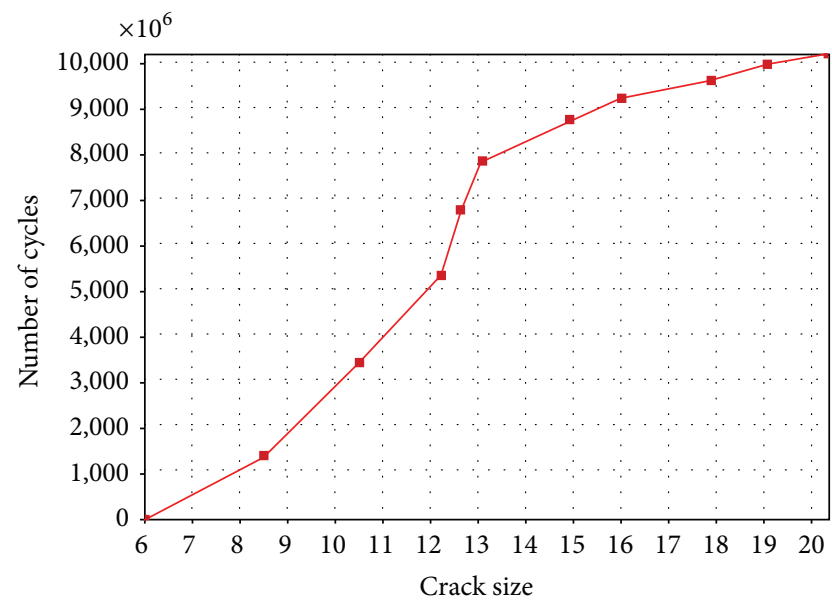

FIGURE 9: Relationship between loading cycle and crack size.

2.2. Dual Boundary Element Method. Dual Boundary Element Method allows analyzing general crack problems in a single-region boundary element. Using dual integral in Dual Boundary Element Method is the boundary integral equation of displacement and traction, which could be described as the equation with Cartesian tensor notation. Without considering the effects of body force, boundary integral could be presented with displacement $\left(u_{i}\right)$ and the location of an inner point $\left(x^{\prime}\right)$ as

$$
\begin{gathered}
u_{i}\left(x^{\prime}\right)+\int_{\Gamma} T_{i j}\left(x^{\prime}, x\right) u_{j}(x) d \Gamma(x) \\
=\int_{\Gamma} U_{i j}\left(x^{\prime}, x\right) t_{j}(x) d \Gamma(x),
\end{gathered}
$$

where $T_{i j}\left(x^{\prime}, x\right)$ and $U_{i j}\left(x^{\prime}, x\right)$ are the traction displacement, respectively, at $x^{\prime}$ of an object. The distance between the source point and the current point is defined as $r$, which is also presented as $\left|x-x^{\prime}\right|$. When the source point approaches the boundary, $r \rightarrow 0$, (2) is presented as a limit transition. The semicircular area around the boundary shown in Figure 1 could be applied to converting the expression to the boundary with the source point so that the entire boundary is divided into two parts, where $\mathrm{G}$ is the original boundary and Ge the boundary of the source point with a semicircular radius $e,(2)$. Consider

$$
\begin{gathered}
u_{i}\left(x^{\prime}\right)+\lim _{\varepsilon \rightarrow 0} \int_{\Gamma-\Gamma_{\varepsilon}+\Gamma^{*}} T_{i j}\left(x^{\prime}, x\right) u_{j}(x) d \Gamma(x) \\
=\lim _{\varepsilon \rightarrow 0} \int_{\Gamma-\Gamma_{\varepsilon}+\Gamma^{*}} U_{i j}\left(x^{\prime}, x\right) t_{j}(x) d \Gamma(x) .
\end{gathered}
$$

In (3), a weakly singular integrand of order $\ln (1 / r)$ is included on the right of the integral expression. When improper integral is limited in order $\ln (1 / r)$ and presents exchangeable properties, it is integrable. On the other hand, when a strongly singular integrand of order is included on the left, it could be regularized with the first Taylor series of displacements, in which the source point could be presented as

$$
\begin{aligned}
& \lim _{\varepsilon \rightarrow 0} \int_{\Gamma-\Gamma_{\varepsilon}+\Gamma^{*}} T_{i j}\left(x^{\prime}, x\right) u_{j}(x) d \Gamma(x) \\
& =\lim _{\varepsilon \rightarrow 0} \int_{\Gamma^{*}} T_{i j}\left(x^{\prime}, x\right)\left[u_{j}(x)-u_{j}\left(x^{\prime}\right)\right] d \Gamma(x) \\
& \quad+u_{j}\left(x^{\prime}\right) \lim _{\varepsilon \rightarrow 0} \int_{\Gamma_{\varepsilon}} T_{i j}\left(x^{\prime}, x\right) d \Gamma(x) \\
& \quad+\lim _{\varepsilon \rightarrow 0} \int_{\Gamma+\Gamma^{*}} T_{i j}\left(x^{\prime}, x\right) u_{j}(x) d \Gamma(x),
\end{aligned}
$$




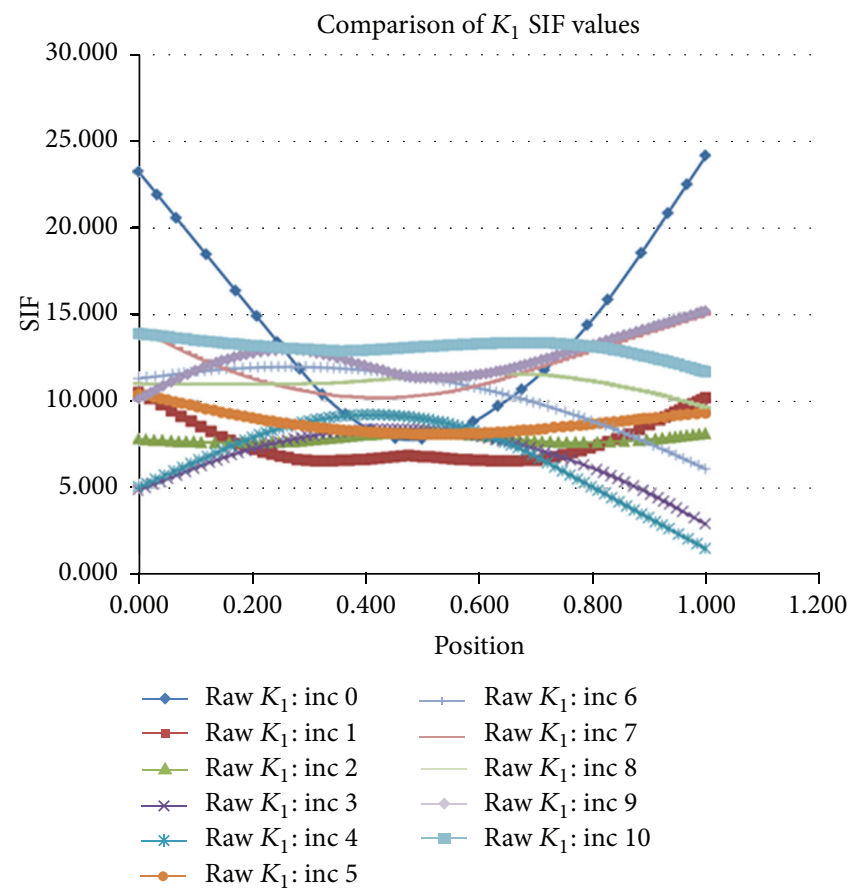

(a)

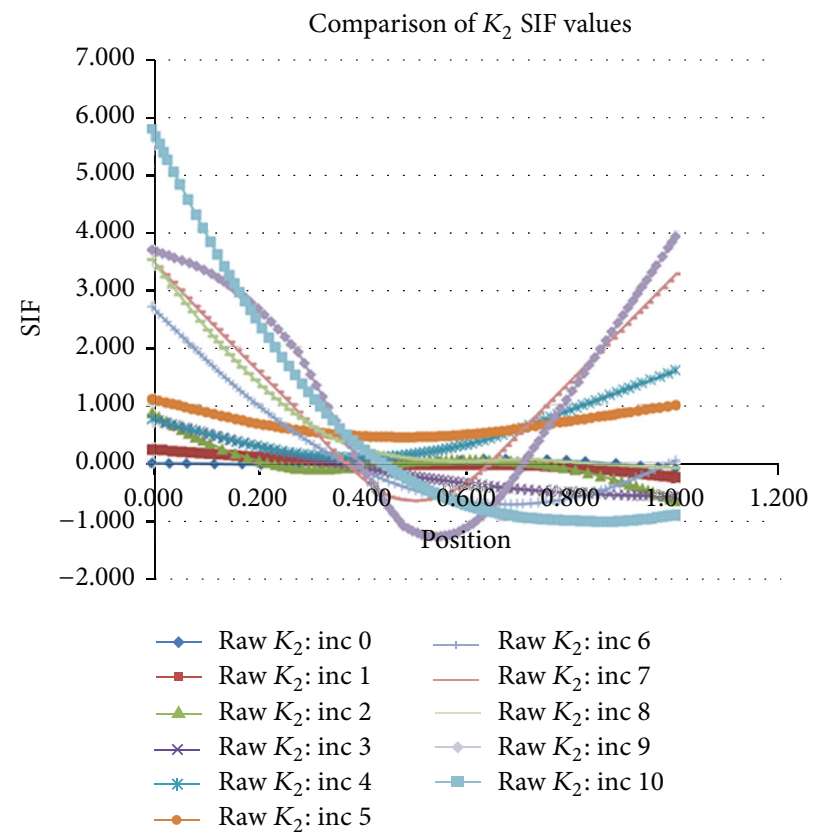

(c)

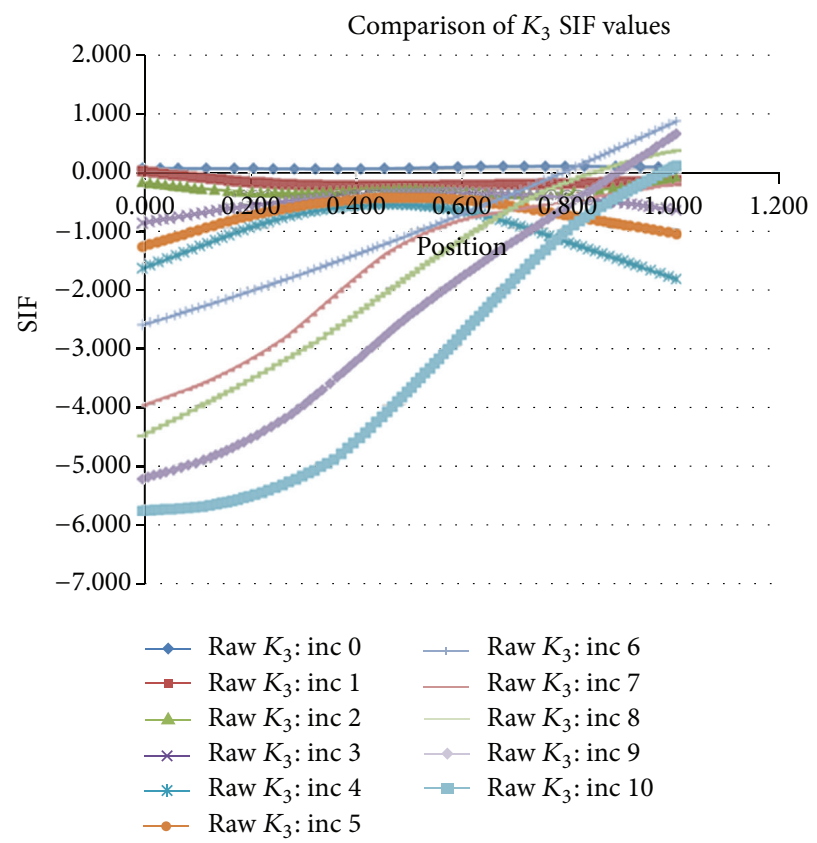

(b)

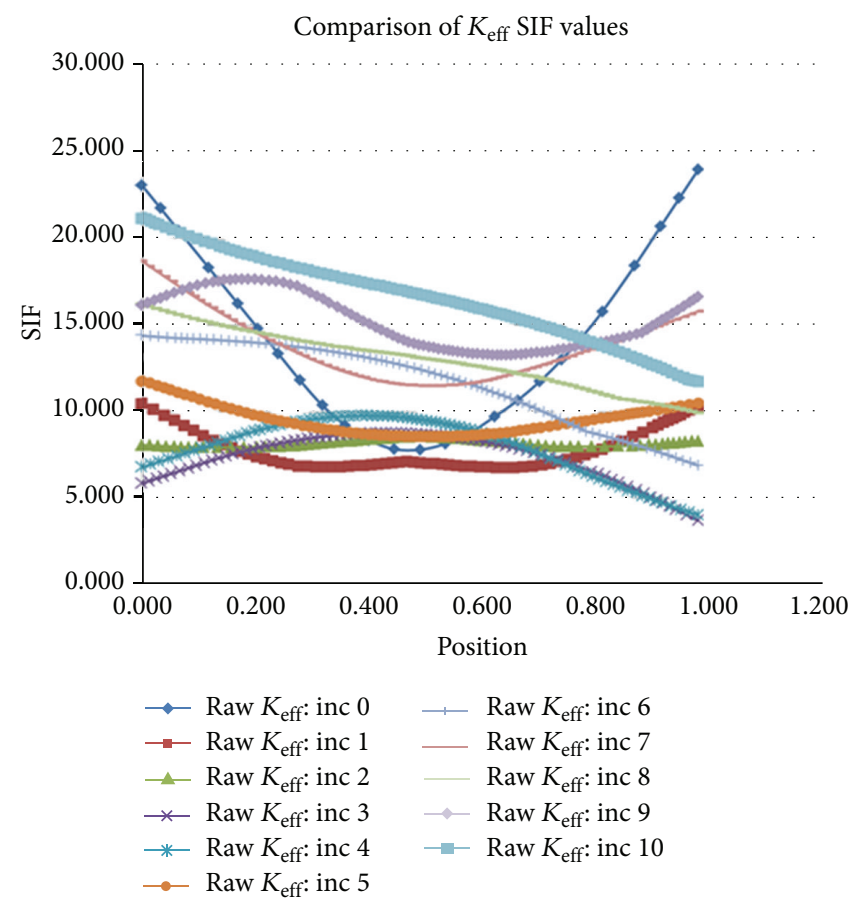

(d)

FIGURE 10: Stress concentration factors of cracks in various crack growing stages.

and the right expression is presented as

$$
\begin{aligned}
& \int_{\Gamma} U_{i j}\left(x^{\prime}, x\right) t_{j}(x) d \Gamma(x) \\
& =c_{i j}\left(x^{\prime}\right) u_{j}\left(x^{\prime}\right)+\int_{\Gamma} T_{i j}\left(x^{\prime}, x\right) u_{j}(x) d \Gamma(x) .
\end{aligned}
$$

Introducing Generalized Hooke's Law in elasticity mechanics, (3) could be converted into

$$
\begin{gathered}
\sigma_{i j}\left(x^{\prime}\right)+\lim _{\varepsilon \rightarrow 0} \int_{\Gamma-\Gamma_{\varepsilon}+\Gamma^{*}} S_{i j k}\left(x^{\prime}, x\right) u_{k}(x) d \Gamma(x) \\
=\lim _{\varepsilon \rightarrow 0} \int_{\Gamma-\Gamma_{\varepsilon}+\Gamma^{*}} D_{i j k}\left(x^{\prime}, x\right) t_{k}(x) d \Gamma(x),
\end{gathered}
$$



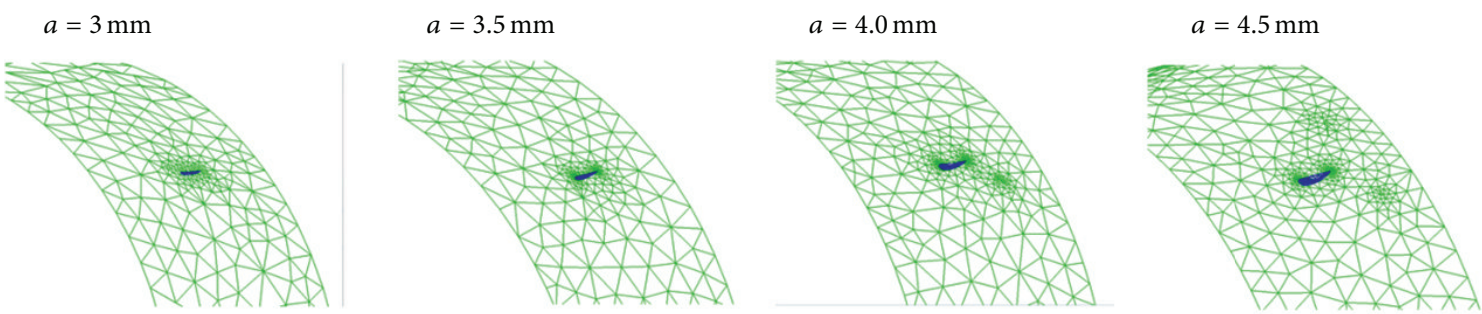
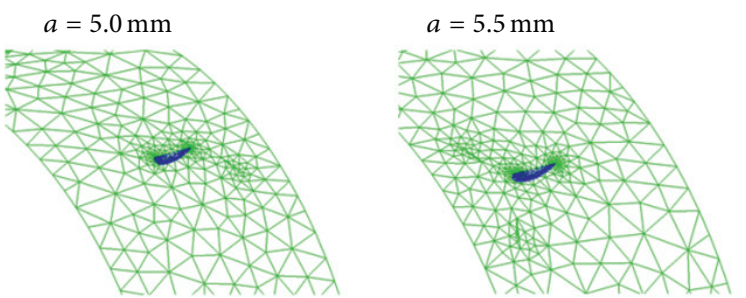

$a=6.0 \mathrm{~mm}$
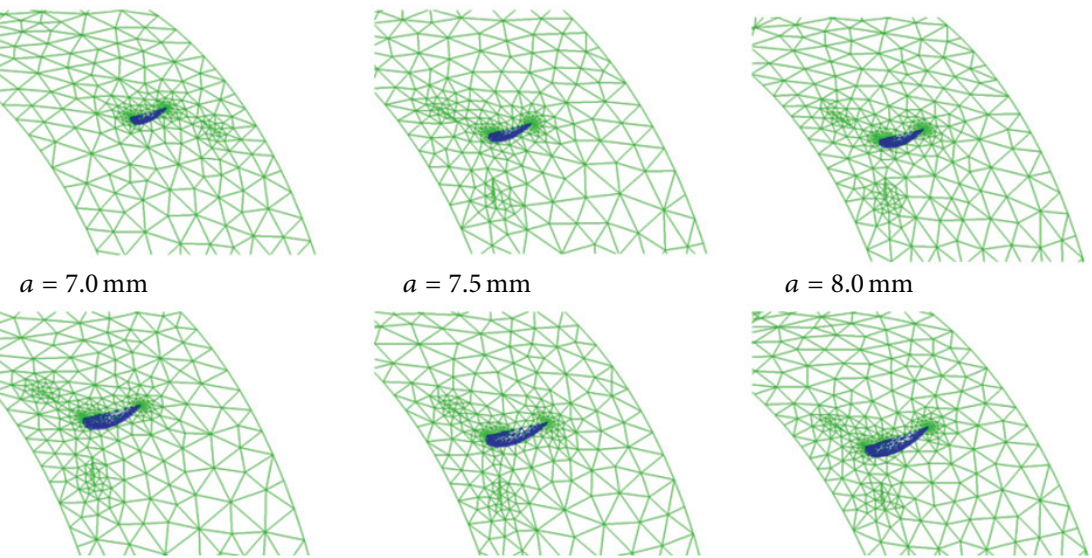

$$
a=7.5 \mathrm{~mm}
$$

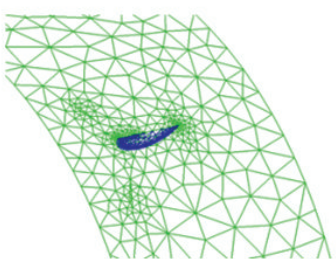

$a=8.0 \mathrm{~mm}$

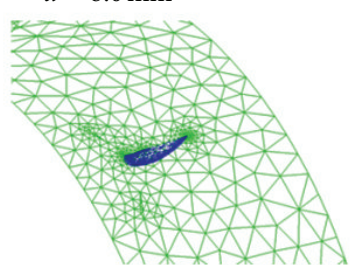

$a=6.5 \mathrm{~mm}$

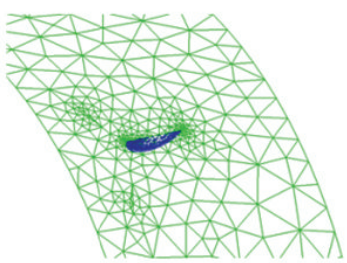

FIGURE 11: Growing shape and size of a longitudinal crack.

where $S_{i j k}\left(x^{\prime}, x\right)$ and $D_{i j k}\left(x^{\prime}, x\right)$ are the differential expressions of $T_{i j}\left(x^{\prime}, x\right)$ and $U_{i j}\left(x^{\prime}, x\right)$, respectively. Combining (5) and (6), the following could be deducted with mathematical algorithm:

$$
\begin{gathered}
\frac{1}{2} t_{j}\left(x^{\prime}\right)+n_{j}\left(x^{\prime}\right)+\int_{\Gamma} S_{i j k}\left(x^{\prime}, x\right) u_{k}(x) d \Gamma(x) \\
=n_{i}\left(x^{\prime}\right) \int_{\Gamma} D_{i j k}\left(x^{\prime}, x\right) t_{k}(x) d \Gamma(x),
\end{gathered}
$$

where $n_{i}$ is defined as the $i$ th component of unit normal vector on the source point boundary. Equations (5) and (7) compose the basic mathematical expression of Dual Boundary Element Method, which could be substituted with proper interpolation function to acquire the physical properties around the singular point.

\section{Research Process}

The entire research process is explained in the previous chapter. Aiming at the introduced software, the practice steps are interpreted in this chapter. The analysis steps are divided into FEM analysis of stress of the material under static stress and BEM analysis of Stress Intensity Factor and the crack growth process. The detailed explanation is shown as follows.

3.1. Static Analysis of Material with ANSYS. The structural analysis with FEM is popular that the principles and steps are no longer repeated, but merely the geometric shape of a pipe, the material property, and the boundary condition are explained. Simplified hypotheses of plane strain are

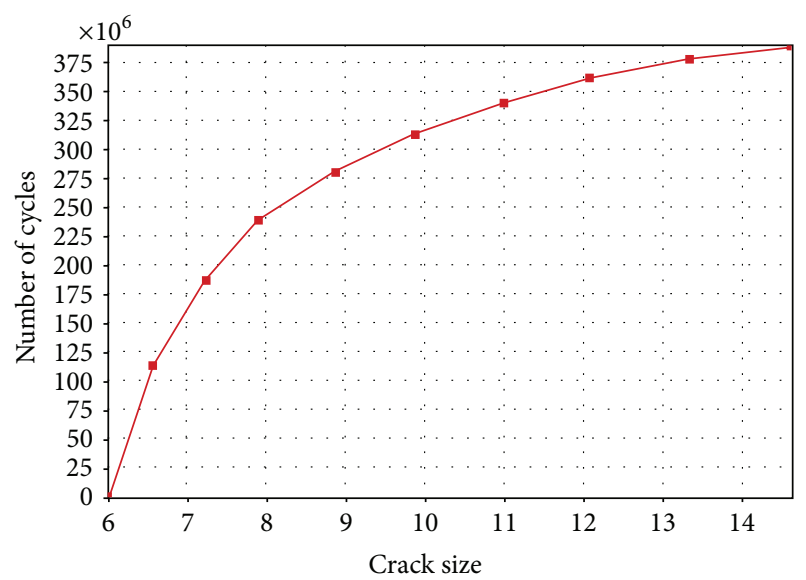

FIgURE 12: Relationship of loading cycle and crack size of a longitudinal crack.

utilized for analyzing a long, strait oil pipe. Nevertheless, in consideration of components presenting horizontal and longitudinal cracks, the 3D geometric shape is analyzed, and the analysis conditions are listed in Table 1 . The longitudinal displacement of the cut-off plane on both ends of the oil pipe is 0 .

Aiming at the initial conditions of an uncorroded oil pipe, the stress distribution is shown in Figure 2, from which the stress distribution is not correlated with the longitudinal position and the stress presents concentric zone. It conforms to the theoretical analysis results, showing the high accuracy of the analysis results. Besides, the von Mises 


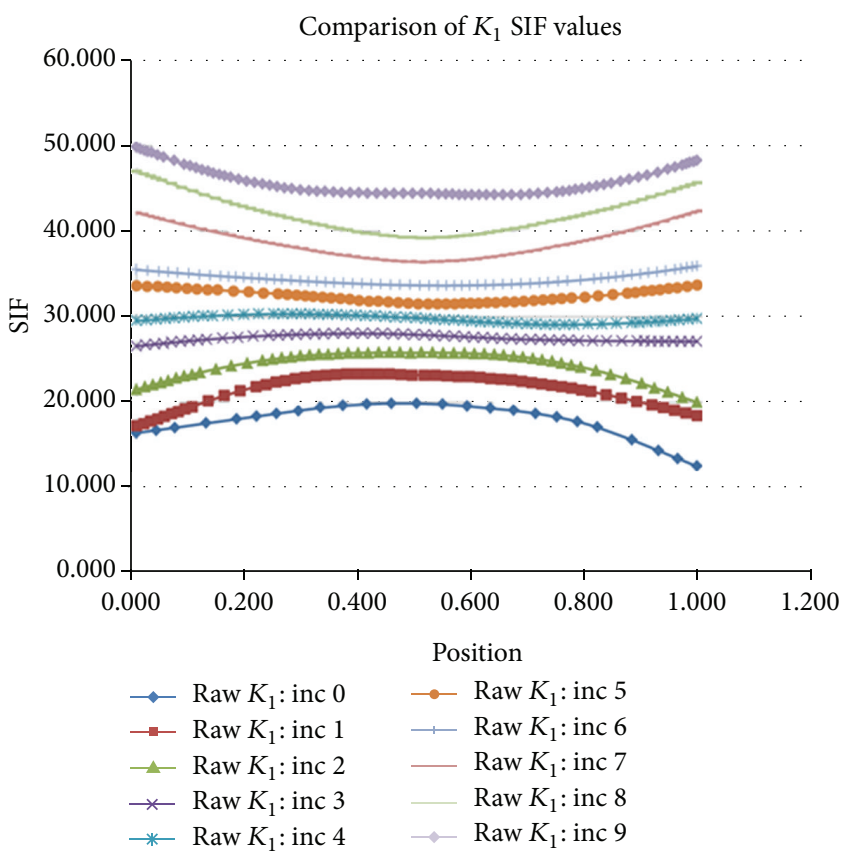

(a)

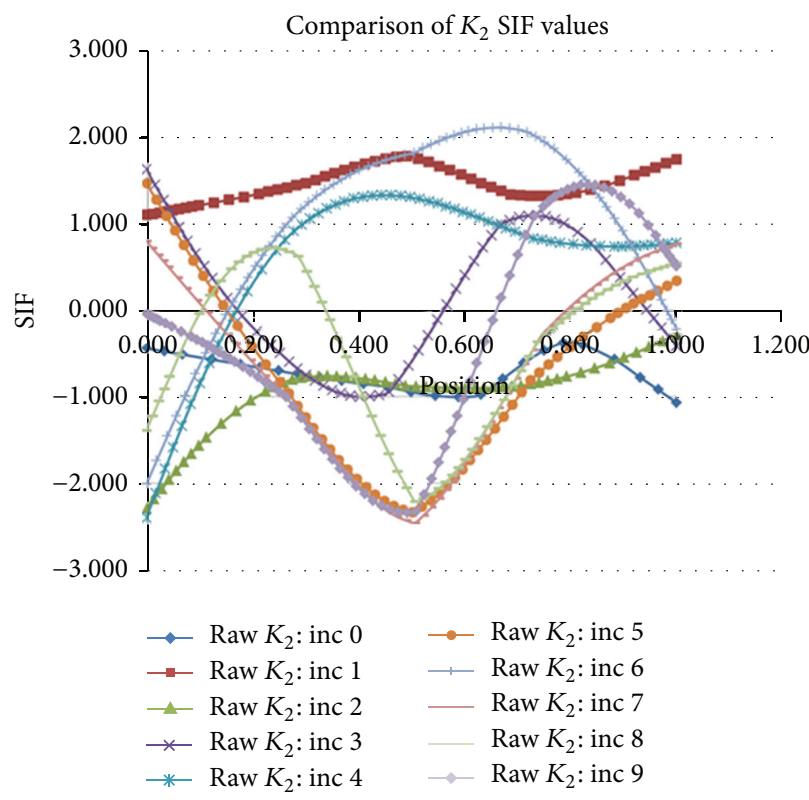

(c)

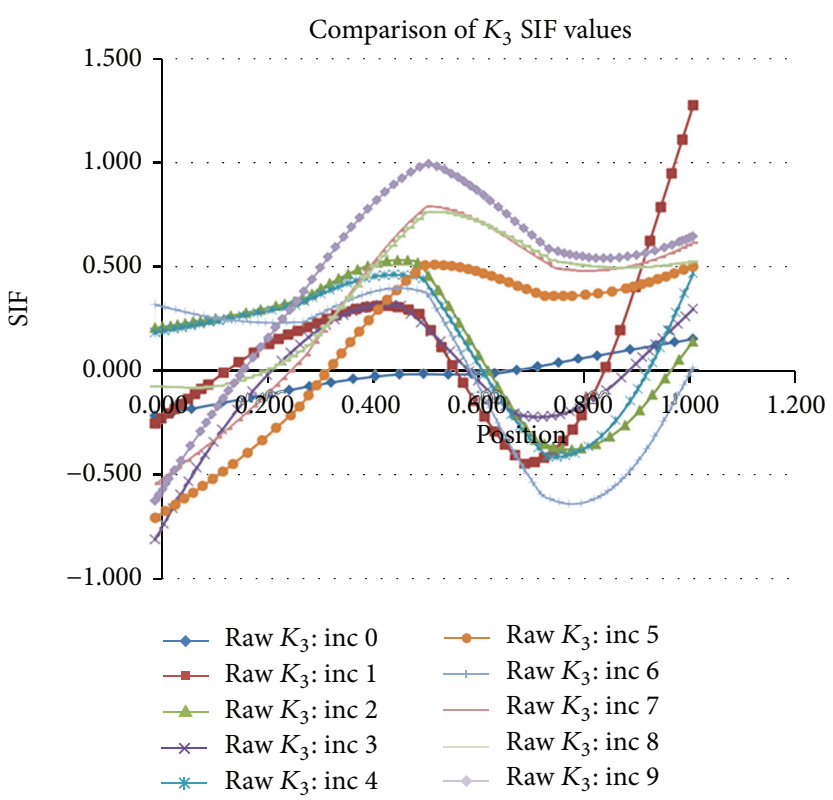

(b)

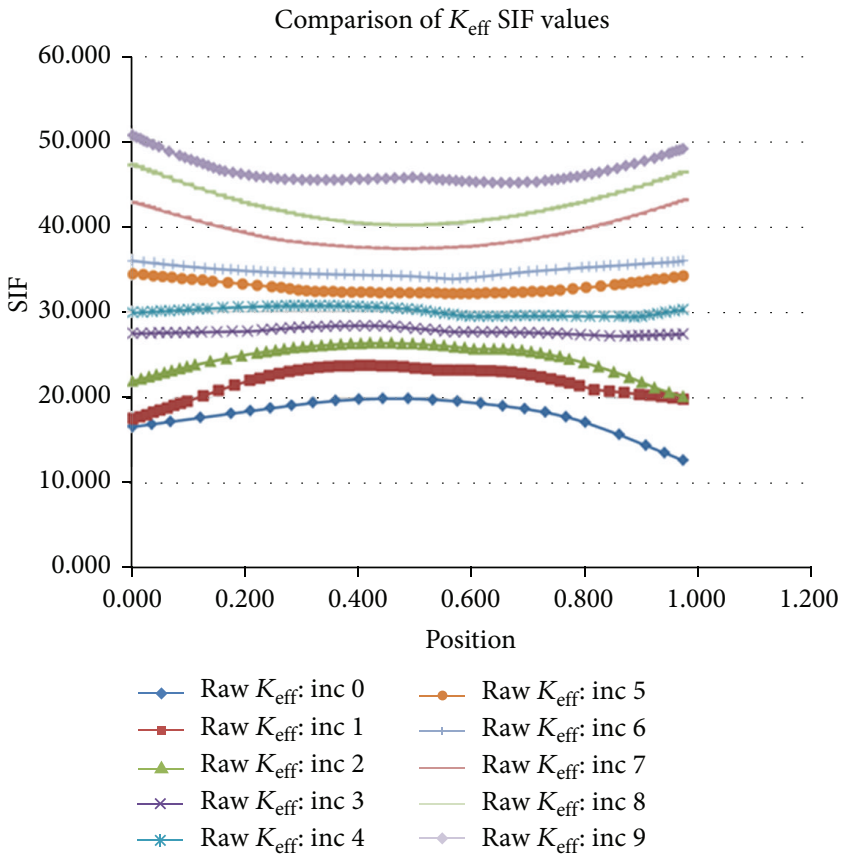

(d)

FiguRE 13: Stress concentration factors of cracks at different growing stages.

stress appears in 9.813-11.635 $\mathrm{MPa}$ and the maximal von Mises stress $11.635 \mathrm{MPa}$ occurs in the inner wall of the oil pipe.

With $10 \mathrm{MHz}$ ultrasonic testing, an oil pipe with uniform corrosion acquired the real thinning value of the pipe wall caused by uniform corrosion, the echo situation, and the thinning situation, Figure 3, where the longitudinal thickness appears in $3.44-4.32 \mathrm{~mm}$. ANSYS is applied to establishing the model and analyzing the pipe wall thickness at various points. The acquired stress distribution is shown in Figure 4, in which the stress changes with metal thinning and the von Mises stress appears in 6.233-41.234 MPa. Although the oil pipe is thinned from $6 \mathrm{~mm}$ to $3.44 \mathrm{~mm}$, which increases the stress, the thinning thickness on the circle is distinct that stress concentration is caused and successive fracture and crack propagation are further caused. 


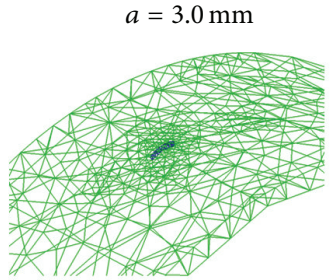

$a=4.5 \mathrm{~mm}$

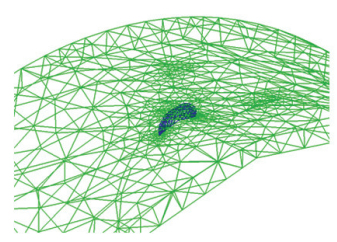

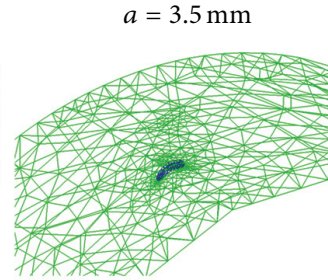

$a=5.0 \mathrm{~mm}$

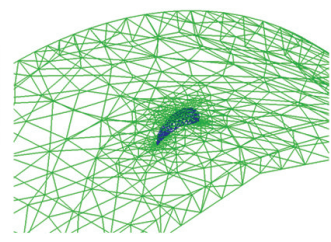

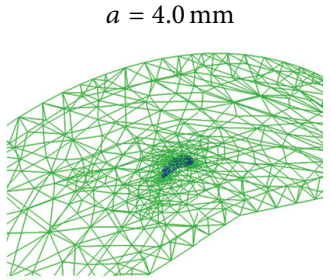

$a=5.5 \mathrm{~mm}$

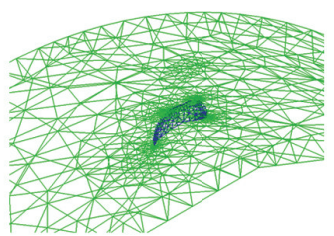

FIGURE 14: Growing shape and size of a circumferential crack on an oil pipe with general metal loss.

TABLE 1: Analysis parameter and material.

\begin{tabular}{lc}
\hline Outer radius & $75 \mathrm{~mm}$ \\
Inner radius & $69 \mathrm{~mm}$ \\
Tube length & $50 \mathrm{~mm}$ \\
Fluid pressure & $1 \mathrm{~N} / \mathrm{mm}^{2}$ \\
Material property & Modulus of elasticity $205 e 3 \mathrm{~N} / \mathrm{mm}^{2}$, \\
& Poisson's ratio 0.29 \\
\hline
\end{tabular}

3.2. Fracture Analysis with BEASY. The analysis model and the results with ANSYS are acquired in the previous chapter. For further fracture mechanics analysis, the crack location and size need to be defined. A conversion program is used for converting the file to the format of BEASY so as to simplify the analysis procedure. The calculation process is shown in Figure 5. Having defined the fatigue cyclic loading properties, the parameters related to fatigue loading analysis are constructed, where the type of analysis element should be set. In the analysis, linear element is directly utilized for accelerating the calculation. Two cases are analyzed in this study, and the selected node and the propagation direction of a crack are described as follows.

(a) Initially installed oil pipe not being corroded and fractured but merely presenting cracks resulted from the production. The crack setting location is shown in Figure 6, in which node 557 is the crack, node 964 is the circumferential crack propagation direction, and node 558 is the longitudinal crack propagation direction.

(b) An oil pipe is with general metal loss corrosion and crack appearing on the maximal thinning area. The crack setting location is shown in Figure 7, where node 1756 is the location of crack, node 1775 is the circumferential crack propagation direction, and node 1755 is the longitudinal crack propagation direction.

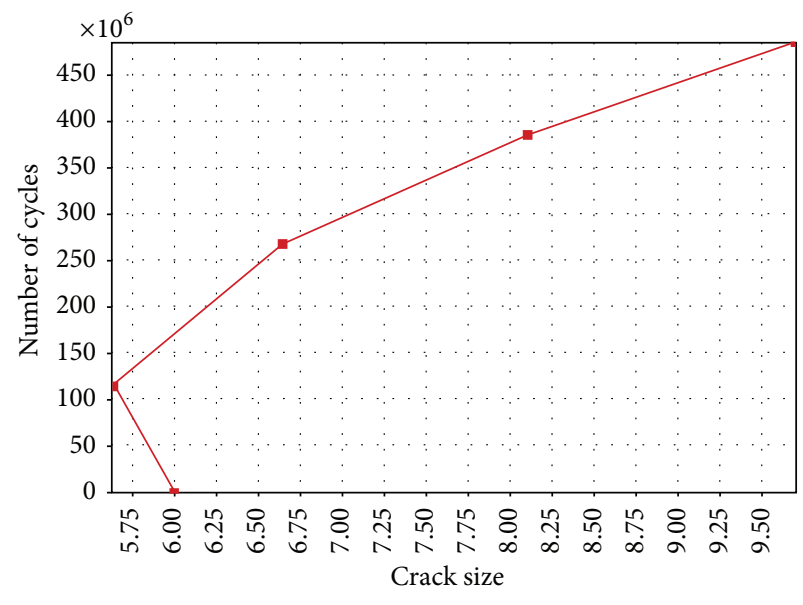

FIGURE 15: Relationship between loading cycle and crack size.

\section{Analysis and Discussion}

According to the above analysis process, two conditions are acquired to make four analysis results, which are elaborately described in the following chapter.

4.1. Initially Installed Oil Pipe Not Being Corroded but Merely Presenting Cracks Resulting from the Production. With the analysis of BEASY, a crack would constantly grow after bearing cyclic loading. Aiming at circumferential crack, the crack shape and size at each stage are calculated, Figure 8. The initial crack presents the length (a) $3.0 \mathrm{~mm}$ and the depth (c) $1.0 \mathrm{~mm}$. From the figure, the crack depth increases with the crack propagation length. When $a=8.0 \mathrm{~mm}$, the crack depth reaches $6.0 \mathrm{~mm}$, which is just the crack propagating to the inner pipe wall. In this case, the analysis would be automatically stopped. The relationship between loading cycle and crack size is shown in Figure 9. The analysis results of crack size ( $2 a)$ and loading cycle are shown in the figure. When the crack size achieves $20.5 \mathrm{~mm}$, the crack has propagated to the inner pipe wall that the oil pipe can no 


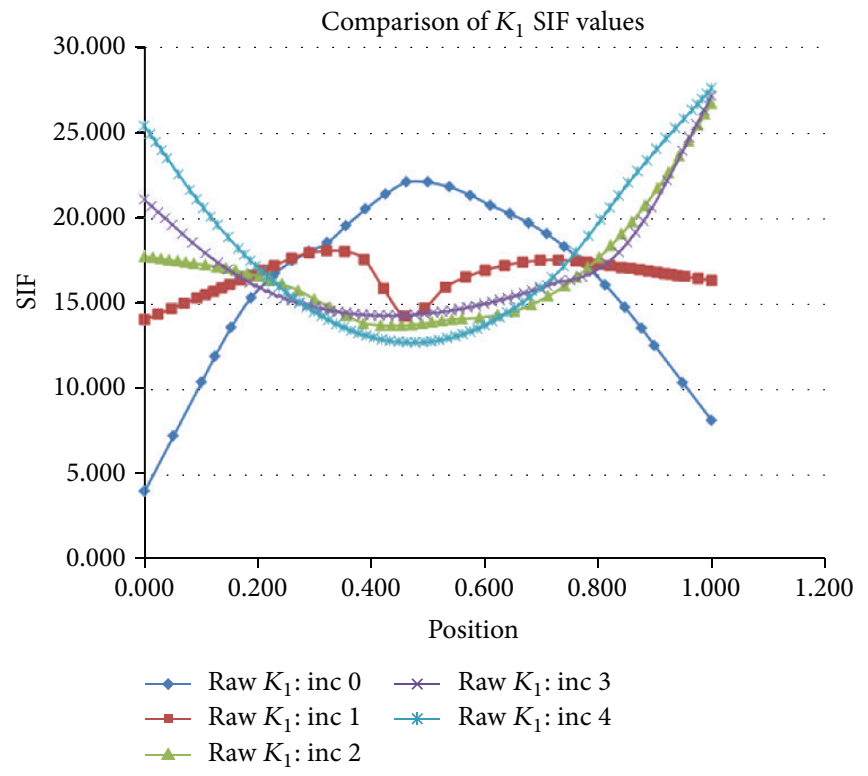

(a)

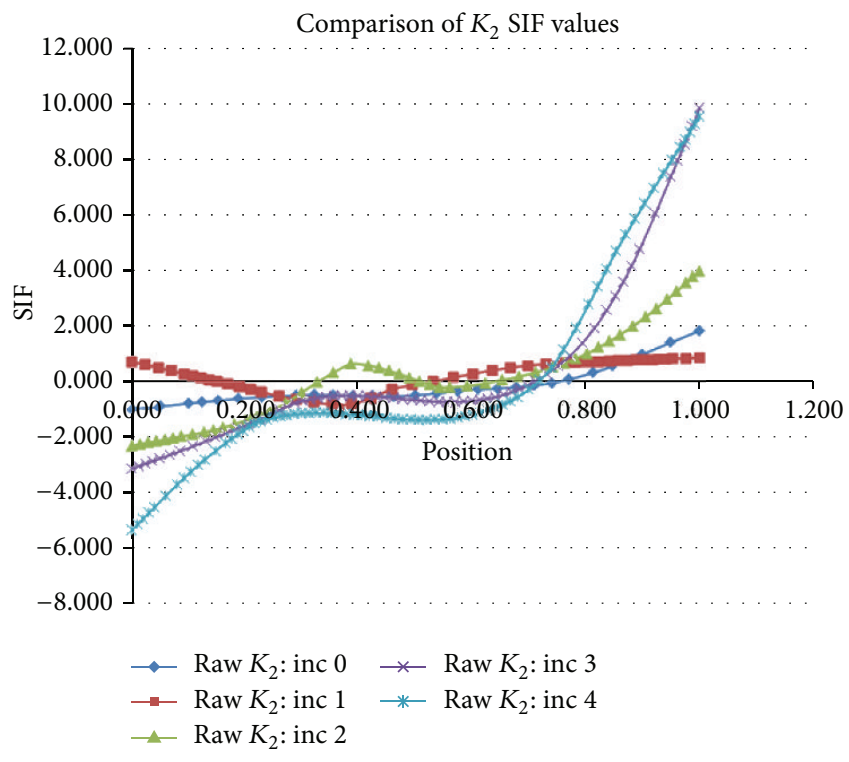

(c)

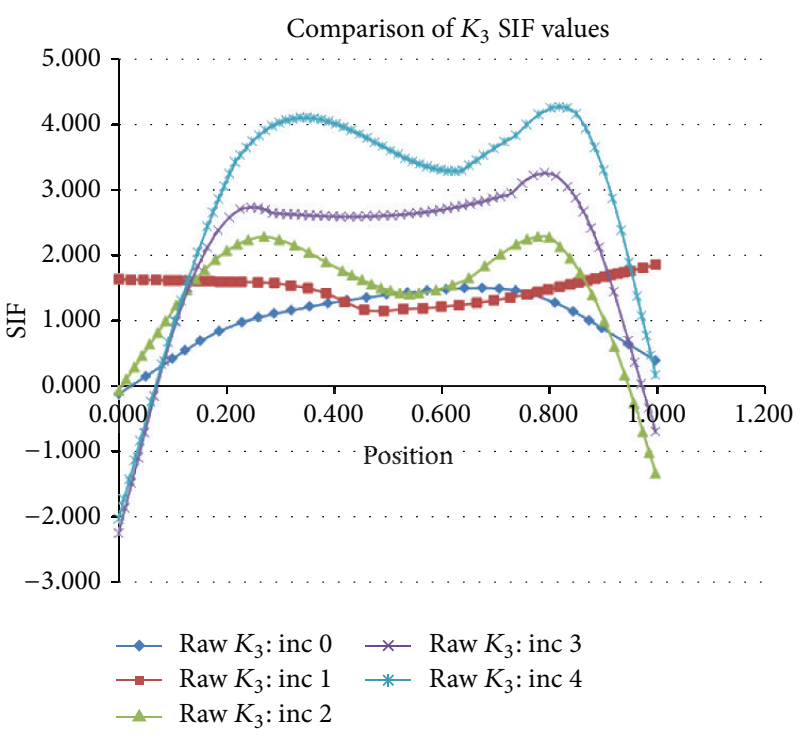

(b)

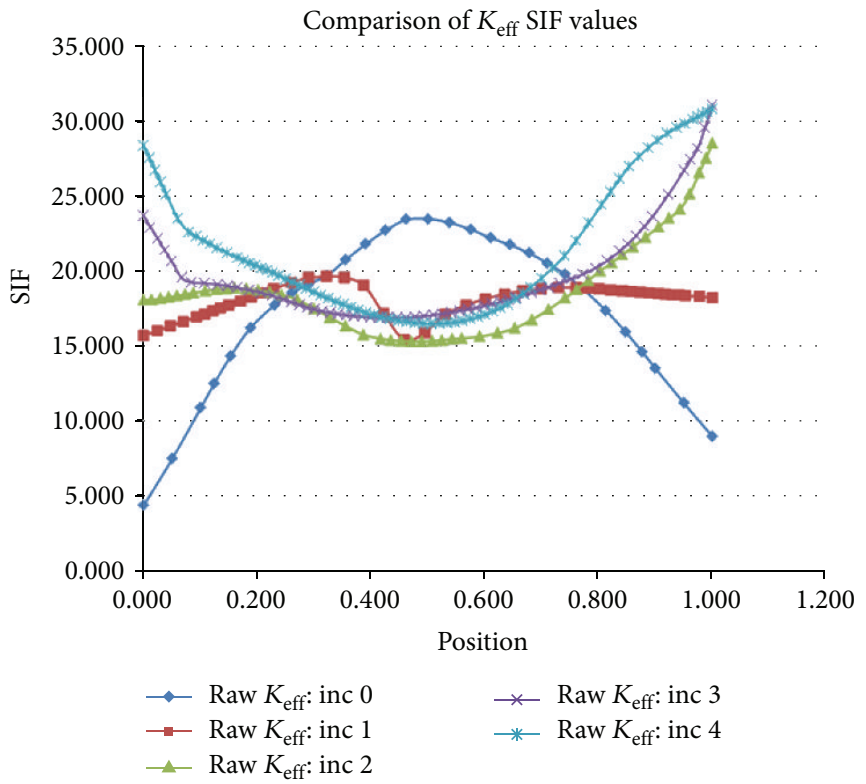

(d)

FIGURE 16: Stress concentration factor of cracks at different growing stages.

longer be used. Meanwhile, the loading cycles are achieved 10.2 billion times, which has exceeded the normally designed life of the material. It implies that an uncorroded oil pipe would not fracture the components by circumferential crack caused in the production. The SIF change at each stage could be further calculated with BEASY, Figure 10. The figure is divided into four parts of $K_{1}, K_{2}, K_{3}$, and $K_{\text {eff }}$; the value of $K_{1}$ is 4-5 times higher than that of $K_{2}$ and $K_{3}$ that the $K_{\text {eff }}$ value is largely affected by $K_{1}$. From the analysis of the $K_{\text {eff }}$ change at various steps, merely SIF under the initial crack shows large change with the crack location. The value would become stable with the crack growth, showing that the crack growth would gradually correct the SIF of the crack tip and the absorbed energy is distributed to the surrounding elastic regions.

Aiming at a longitudinal crack, the crack shape and size at each stage are calculated, Figure 11. The initial crack shows the length (a) $3.0 \mathrm{~mm}$ and the depth (c) $1.0 \mathrm{~mm}$. From the figure, the crack depth increases with the crack propagation length. When $a=8.0 \mathrm{~mm}$, the crack depth reaches $6.0 \mathrm{~mm}$, which is just the crack propagating to the inner pipe wall. The analysis process therefore would be automatically stopped. Moreover, the element distribution at each stage is distinct; especially, the individual grid at the crack tip is even finer. 


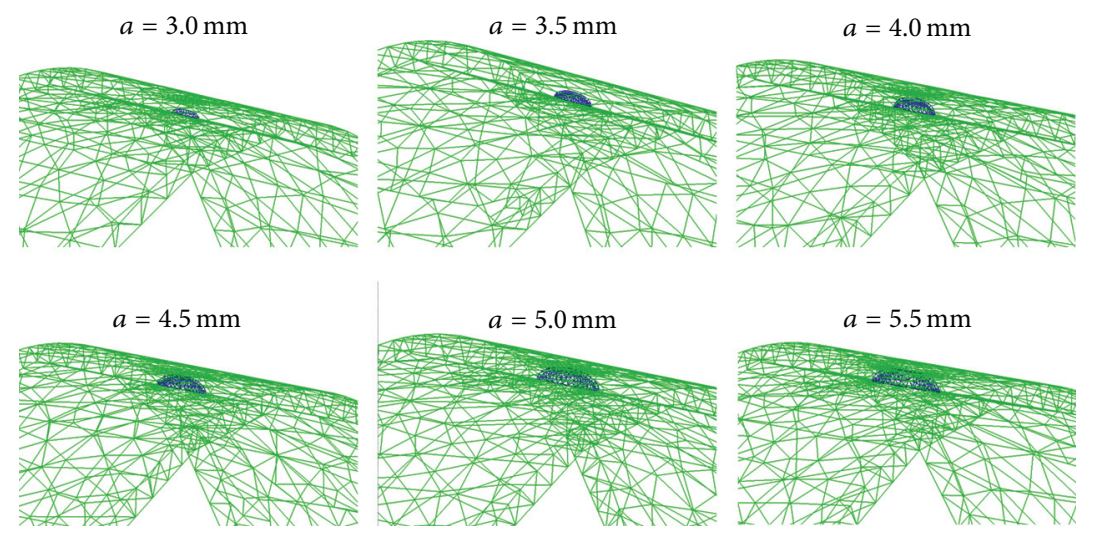

FIGURE 17: Growing shape and size of a longitudinal crack.

The relationship between loading cycle and crack size is shown in Figure 12. From the analysis results of crack size (2a) and loading cycle, the number of loading cycles is achieved 0.385 billion times when the crack size is $14.5 \mathrm{~mm}$. It has far exceeded the normally designed life of material. It implies that an uncorroded oil pipe would hardly fracture the components by a longitudinal crack. The SIF change at each stage is further calculated with BEASY, Figure 13. The figure is divided into four parts of $K_{1}, K_{2}, K_{3}$, and $K_{\text {eff. The }}$ value of $K_{1}$ is 2-30 times higher than that of $K_{2}$ and $K_{3}$ that the $K_{\text {eff }}$ value is largely affected by $K_{1}$. From the analysis of $K_{\text {eff }}$ change in each step, SIF in the initial crack state and the constant propagation does not reveal large change with the crack location. The enlarging value presents the growth crack enhancing the SIF.

4.2. Oil Pipe with General Metal Loss Corrosion and the Crack Appearing on the Maximal Thinning Area. With the analysis of BEASY, an oil pipe with general metal loss corrosion is analyzed. The crack would constantly grow after bearing cyclic loading. Aiming at circumferential crack, the crack shape and size at each stage are calculated, Figure 14. The initial crack reveals the length $(a)$ of $3.0 \mathrm{~mm}$ and the depth (c) of $1.0 \mathrm{~mm}$. The crack depth would increase with the crack propagation length. When $a=5.5 \mathrm{~mm}$, the crack depth achieves $3.5 \mathrm{~mm}$, which is just the crack propagating to the inner pipe wall. The analysis process is then automatically stopped. Furthermore, the element distribution at each stage is distinct; especially, the individual grid is finer at the crack tip. The relationship between loading cycle and crack size is shown in Figure 15. From the analysis results of crack size (2a) and loading cycle, the initial crack length-depth ratio is so large that the crack length is reduced in the initial stage. When the crack depth reaches $1.25 \mathrm{~mm}$, the crack would release the blocking state and start to show linear opening properties. When the crack size achieves $9.75 \mathrm{~mm}$, the crack has propagated to the inner pipe wall that the oil pipe can no longer be used. Meanwhile, the number of loading cycles is achieved 0.475 billion times, which has exceeded the normally designed life of material. It also implies that a corroded oil pipe would not fracture the components by circumferential cracks, even when there is thinning. The

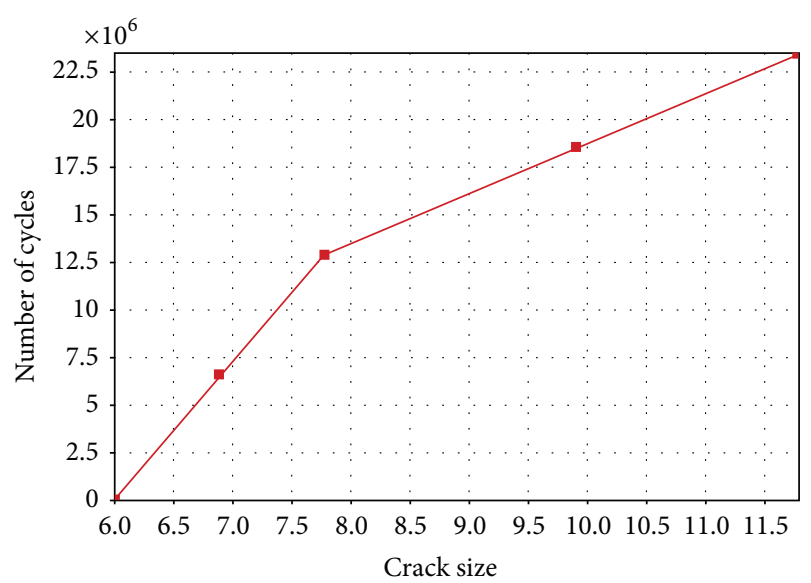

FIGURE 18: Relationship between loading cycle and crack size of a longitudinal crack.

SIF change at each stage is further calculated with BEASY, Figure 16. The figure is divided into $K_{1}, K_{2}, K_{3}$, and $K_{\text {eff }}$. The value of $K_{1}$ is larger than that of $K_{2}$ and $K_{3}$. When analyzing the $K_{\text {eff }}$ change at each step, merely the SIF of crack at initial state would change the trend with crack locations, which is different from the situations at other stages. With the crack growth, the $K_{\text {eff }}$ value at the second stage becomes stable and the upward concave shows the increasing $K_{\text {eff }}$ value.

Aiming at a longitudinal crack, the crack shape and size at each stage are calculated, Figure 17. The initial crack shows the length $(a)$ of $3.0 \mathrm{~mm}$ and the depth $(c)$ of $1.0 \mathrm{~mm}$. From the figure, the crack depth increases with the crack propagation length. When $a=5.5 \mathrm{~mm}$, the crack depth reaches $3.5 \mathrm{~mm}$, which is just the crack propagating to the inner pipe wall. The analysis process is then automatically stopped. Moreover, the element distribution at each stage is distinct; especially, the individual grid is finer at the crack tip. The relationship between loading cycle and crack size is shown in Figure 18. From the analysis results of crack size (2a) and loading cycles, the loading cyclic presents 23 million times when the crack size reaches $11.8 \mathrm{~mm}$, showing the designed life of material should be taken into account. 


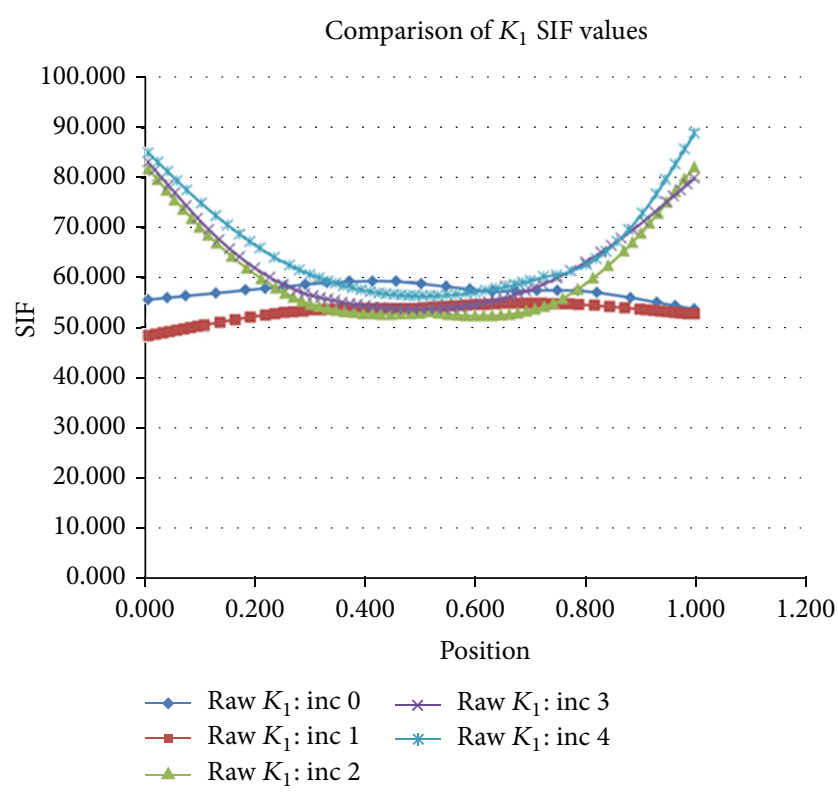

(a)

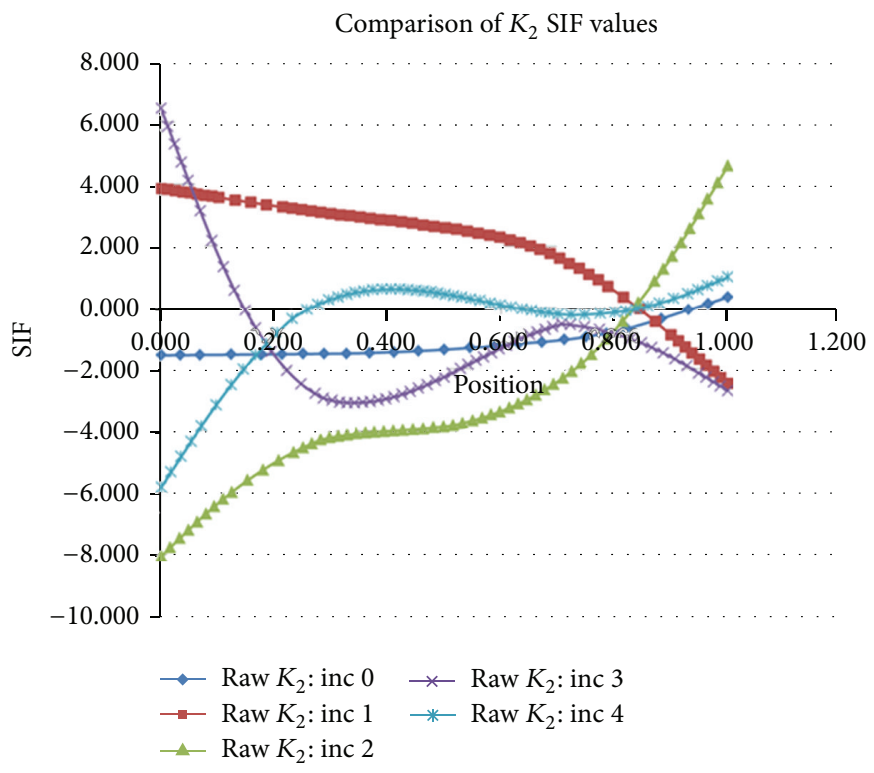

(c)

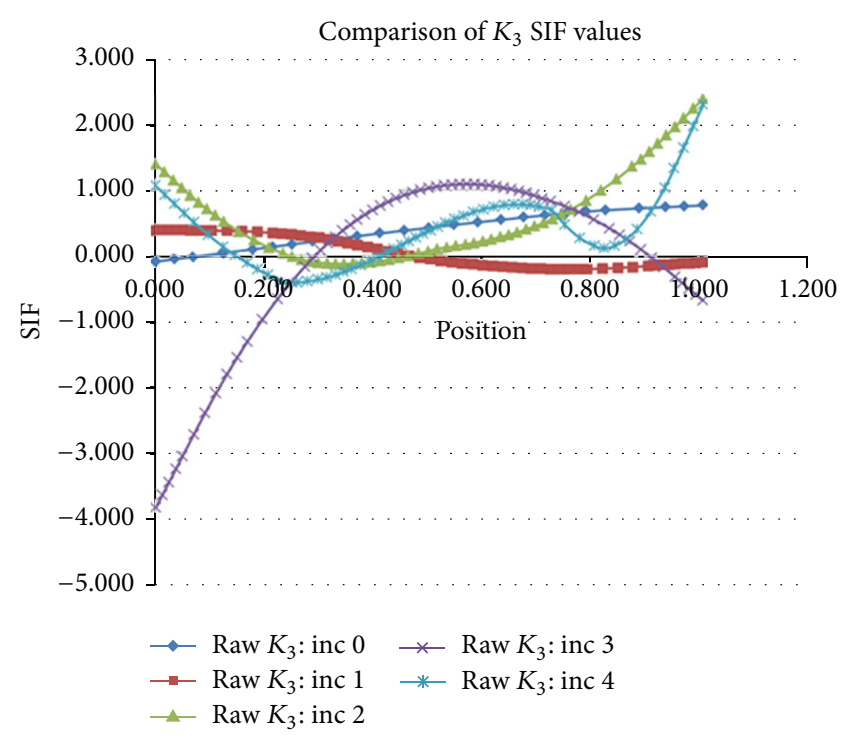

(b)

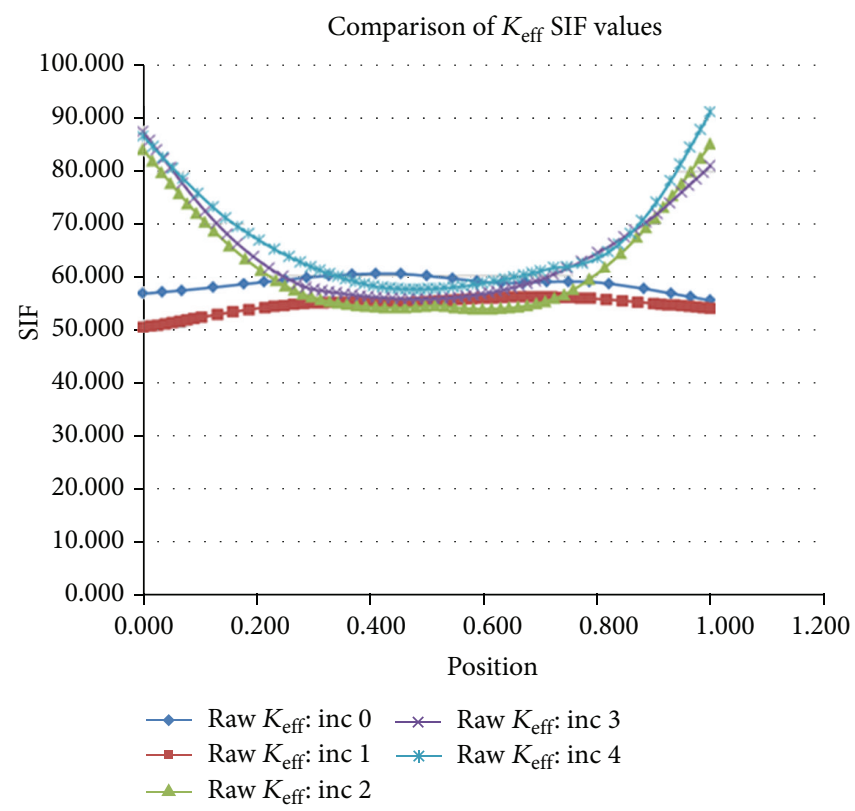

(d)

FIGURE 19: Stress concentration factor of cracks at various growing stages.

It also implies that a corroded oil pipe would fracture the components by a longitudinal crack. The SIF change at each stage could be further calculated with BEASY, Figure 19. The figure is divided into $K_{1}, K_{2}, K_{3}$, and $K_{\text {eff. The value of }}$ $K_{1}$ is 10-40 times higher than that of $K_{2}$ and $K_{3}$ that the $K_{\text {eff }}$ value is largely affected by $K_{1}$. From the analysis of $K_{\text {eff }}$ change at each step, the SIF in the initial crack state and the constant propagation does not show large change with crack locations. The increasing value presents the growing crack that SIF would be constantly enhanced. Based on the four cases with fracture mechanics analysis, the final statistical data are organized in Table 2.

\section{Conclusion}

According to the above research process and the case analyses of two types of oil pipe crack, the following results are concluded.

(a) The crack growth resulting in fracture in the actual loading process of an uncorroded oil pipe can be ignored as the calculated fatigue loading cycle is extremely high. However, when there is corrosion on the oil pipe, the fatigue loading cycle decreases rapidly, showing that corrosion could easily result in fatigue fracture on a metal oil pipe. 
TABLE 2: Crack growth property on the oil pipe with different corrosion conditions.

\begin{tabular}{lcccc}
\hline Pipe type & \multicolumn{2}{c}{ Uncorroded oil pipe } & \multicolumn{2}{c}{ Oil pipe with general metal loss } \\
\hline Crack direction & Circumferential direction & Longitudinal direction & Circumferential direction & Longitudinal direction \\
\hline Final crack length $(\mathrm{mm})$ & 20.3678 & 14.6009 & 9.7177 & 11.7790 \\
\hline Final crack depth $(\mathrm{mm})$ & 6.6421 & 6.5192 & 3.0931 & 3.3278 \\
\hline Fatigue loading cycle (times) & $10,245,885,974$ & $390,583,049$ & $483,412,414$ & $23,537,533$ \\
\hline $\begin{array}{l}\text { Maximal effective SIF in crack } \\
\text { growing process }\left(\mathrm{MPa} \cdot \mathrm{m}^{1 / 2}\right)\end{array}$ & 22.128 & 49.908 & 30.379 & 86.650 \\
\hline
\end{tabular}

(b) From the research results, the longitudinal stress of an oil pipe, which bears internal pressure, is larger than the circumferential one that the maximal fatigue loading cycle of a circumferential crack is higher than that of a longitudinal one.

(c) From the growing length and depth of a crack, the final aspect ratio of crack size appears in 2.42-3.37 and 2.71-3.42 on the circumferential and longitudinal direction, respectively. The difference is not large, presenting the isotropic material property of metal.

(d) The crack growth and the correspondent fatigue loading cycle are determined. The ratios of loading cycles of circumferential and longitudinal crack are 26.23 and 20.54 for uncorroded and general metal loss oil pipe, respectively. It shows the stress level is the dominant factor for the crack growth.

\section{Conflict of Interests}

The author declares that there is no conflict of interests regarding the publication of this paper.

\section{References}

[1] R. H. Gallagher, "A review of finite element techniques in fracture mechanics," in Proceedings of the 1st Conference on Numerical Methods in Fracture Mechanics, A. R. Luxmoore and D. R. J. Owen, Eds., pp. 1-25, University College of Swansea, 1978.

[2] J. R. Rice and D. M. Tracey, "Computational fracture mechanics," in Methods in Structural Mechanics, Academic Press, New York, NY, USA, 1973.

[3] S.-Y. Hsia, "Optimization of microextrusion preforming using taguchi method," Mathematical Problems in Engineering, vol. 2013, Article ID 305797, 9 pages, 2013.

[4] S.-Y. Hsia and P.-Y. Shih, "Wear analysis of forging die for long hex flange nuts," Advances in Materials Science and Engineering. In press.

[5] Y.-T. Chou and S.-Y. Hsia, "Numerical analysis of indoor sound quality evaluation using finite element method," Mathematical Problems in Engineering, vol. 2013, Article ID 420316, 8 pages, 2013.

[6] C. A. Brebbia and J. Dominguez, Boundary Elements-An Introductory Course, Southampton, UK, Computational Mechanics, 1989.

[7] M. D. Snyder and T. A. Cruse, "Boundary-integral equation analysis of cracked anisotropic plates," International Journal of Fracture, vol. 11, no. 2, pp. 315-328, 1975.
[8] S. L. Crouch, "Solution of plane elasticity problems by the displacement discontinuity method. I. Infinite body solution," International Journal for Numerical Methods in Engineering, vol. 10, no. 2, pp. 301-318, 1976.

[9] G. E. Blandford, A. R. Ingraffea, and J. A. Liggett, "Twodimensional stress intensity factor computations using the boundary element method," International Journal for Numerical Methods in Engineering, vol. 17, no. 3, pp. 387-404, 1981.

[10] J. T. Chen and H.-K. Hong, "Review of dual boundary element methods with emphasis on hypersingular integrals and divergent series," Applied Mechanics Reviews, vol. 52, no. 1, pp. 17-32, 1999.

[11] H. F. Bueckner, "Field singularities and related integral representations," in Methods of Analysis and Solutions of Crack Problems, G. C. Sih, Ed., vol. 1 of Mechanics of Fracture, pp. 239314, Springer, Dordrecht, The Netherlands, 1973.

[12] J. O. Watson, "Hermitian cubic boundary elements for the analysis of cracks of arbitrary geometry," in Advanced Boundary Element Methods, T. A. Cruse, Ed., International Union of Theoretical and Applied Mechanics, pp. 465-474, Springer, Berlin, Germany, 1988.

[13] H. Hong and J. Chen, "Derivations of integral equations of elasticity," Journal of Engineering Mechanics, vol. 114, no. 6, pp. 1028-1044, 1988.

[14] L. J. Gray, Boundary Element Method for Regions with Thin Internal Cavities, IBM Bergen Scientific Centre, Bergen, Norway, 1987.

[15] L. J. Gray, L. F. Martha, and A. R. Ingraffea, "Hypersingular integrals in boundary element fracture analysis," International Journal for Numerical Methods in Engineering, vol. 29, no. 6, pp. 1135-1158, 1990.

[16] P. H. Wen, M. H. Aliabadi, and D. P. Rooke, "Cracks in three dimensions: a dynamic dual boundary element analysis," Computer Methods in Applied Mechanics and Engineering, vol. 167, no. 1-2, pp. 139-151, 1998.

[17] D. N. dell'Erba and M. H. Aliabadi, "BEM analysis of fracture problems in three-dimensional thermoelasticity using $J$ integral," International Journal of Solids and Structures, vol. 38, no. 26-27, pp. 4609-4630, 2001.

[18] X. Lu and W.-L. Wu, "A subregion DRBEM formulation for the dynamic analysis of two-dimensional cracks," Mathematical and Computer Modelling, vol. 43, no. 1-2, pp. 76-88, 2006.

[19] L. K. Keppas and N. K. Anifantis, "Fatigue life prediction under cyclic thermal loads using the boundary elements method for two-dimensional problems," Computers \& Structures, vol. 89, no. 7-8, pp. 590-598, 2011.

[20] A. N. Guz, I. A. Guz, A. V. Men'Shikov, and V. A. Men'Shikov, "Three-dimensional problems in the dynamic fracture mechanics of materials with interface cracks (review)," International Applied Mechanics, vol. 49, no. 1, pp. 1-61, 2013. 

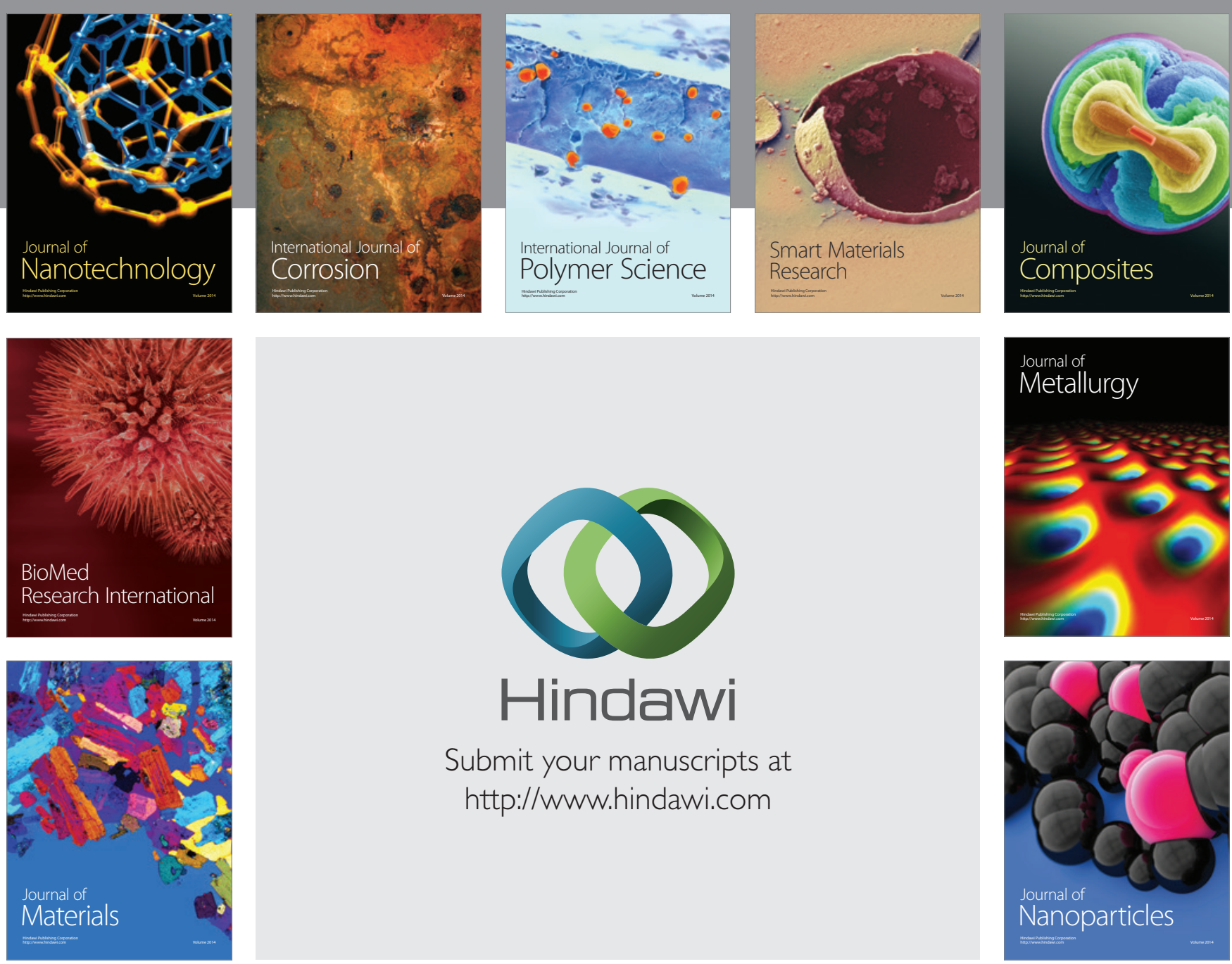

Submit your manuscripts at http://www.hindawi.com
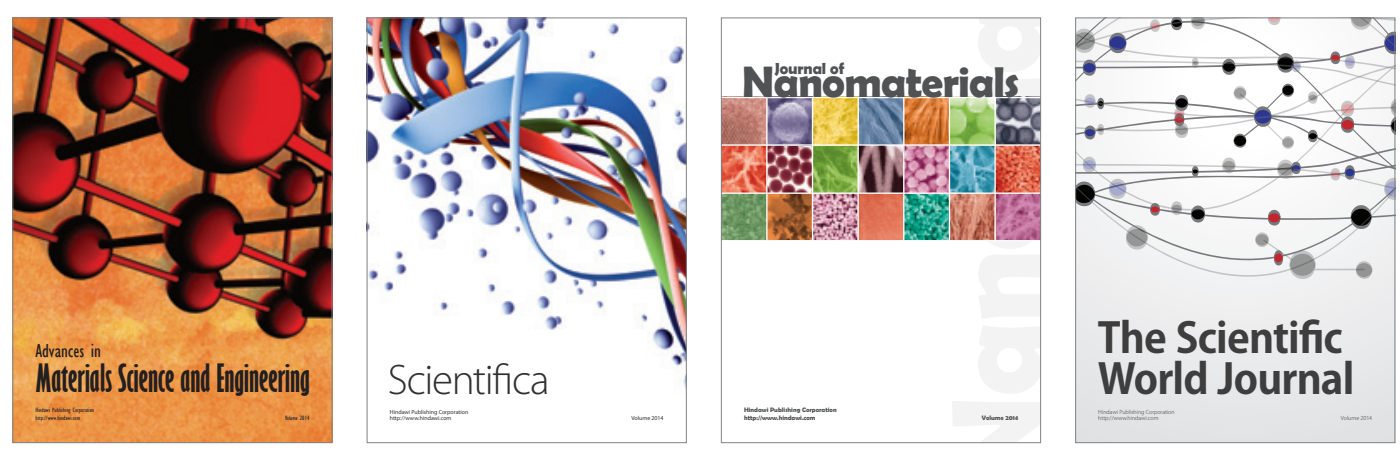

\section{The Scientific World Journal}
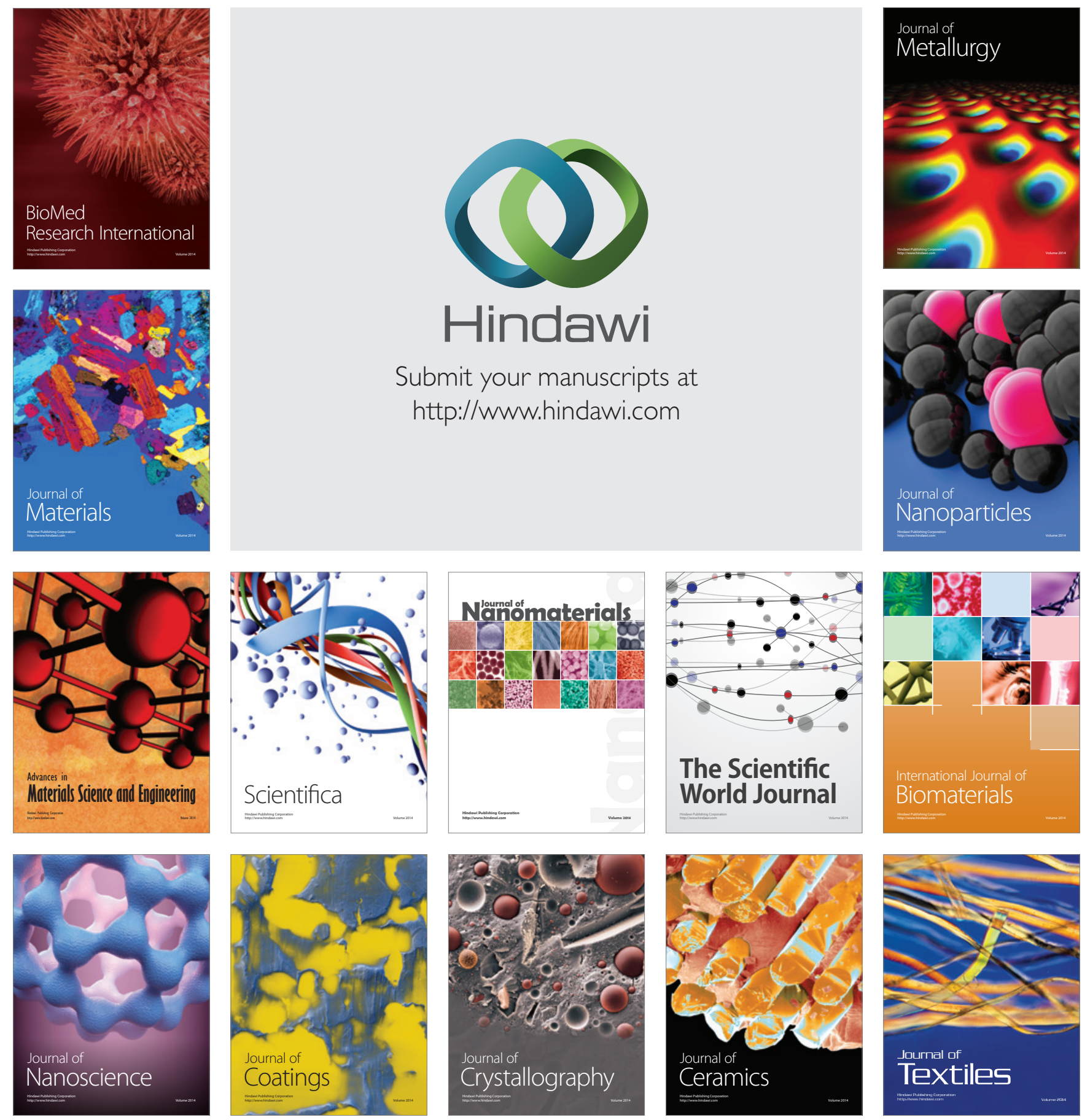